Article

\title{
A Study on Fiscal Risk of China's Employees Basic Pension System under Longevity Risk
}

\author{
Min Le ${ }^{1, *}$, Xinrong Xiao $^{2}$, Dragan Pamučar ${ }^{3}(\mathbb{D})$ and Qianling Liang ${ }^{4}$ \\ 1 School of Economics and Management, Zhejiang Business Technology Institute, Ningbo 315012, China \\ 2 School of Banking and Finance, University of International Business and Economics, Beijing 100029, China; \\ xiaoxinrong@uibe.edu.cn \\ 3 Department of Logistics, University of Defence, 11000 Belgrade, Serbia; dpamucar@gmail.com \\ 4 School of Insurance, Central University of Finance and Economics, Beijing 102206, China; lq1111_222@163.com \\ * Correspondence: nculemin@163.com; Tel.: +86-135-6664-6872
}

check for updates

Citation: Le, M.; Xiao, X.; Pamučar D.; Liang, Q. A Study on Fiscal Risk of China's Employees Basic Pension System under Longevity Risk. Sustainability 2021, 13, 5526. https:// doi.org/10.3390/su13105526

Academic Editor: Michael McAleer

Received: 12 April 2021

Accepted: 13 May 2021

Published: 15 May 2021

Publisher's Note: MDPI stays neutral with regard to jurisdictional claims in published maps and institutional affiliations.

Copyright: (c) 2021 by the authors. Licensee MDPI, Basel, Switzerland This article is an open access article distributed under the terms and conditions of the Creative Commons Attribution (CC BY) license (https:// creativecommons.org/licenses/by/ $4.0 /)$.

\begin{abstract}
It is generally accepted that China's Employees Basic Pension System (CEBPS) cannot cover its expenses. The government needs to fill the gap in income and expenditure with fiscal revenue to ensure sustainability of the system, which may cause it to take fiscal risk caused by the volatility of the fund gap. In this article, through the establishment of a prediction model for the income and expenditure of CEBPS with dynamic mortality, we aimed to measure the fiscal risk caused by longevity risk and provide policy basis for the government. We found that longevity risk leads to serious fiscal risk. The income and expenditure gap of CEBPS fluctuates greatly, and the $2.5 \%$ and 97.5\% quantiles of fund balance in 2067 are 1.52 and 0.44 times the expected value, respectively. The knock-on effect of fiscal risk, measured by value-at-risk (VaR), is 1.15 times gross domestic product and 4.75 times state fiscal expenditure in 2020. In this article, we not only calculate the expected value like the other literatures but also discuss the volatility of the CEBPS fund gap.
\end{abstract}

Keywords: China's Employees Basic Pension System; dynamic stochastic model; the fund gap; fiscal risk; longevity risk

\section{Introduction}

With the advancement of medical technology and improvement in living standards, the life expectancy of the population continues to increase. The resulting longevity risk threatens the sustainable operation of public pension systems in various countries [1-5]. In China, according to "World Health Statistics 2014" and "World Health Statistics 2018", the average life expectancy of the population increased by 6 years from 1990 to 2012 and by 1.4 years from 2012 to 2016 . Life expectancy increases rapidly. At the same time, the family planning policy of the 1980s caused a sharp drop in the proportion of the current working population aged 15 to 65 years. The proportion of the working population reached $73.05 \%$ in 2009 and dropped to $71.02 \%$ in 2018 , a decrease of 2.03 percentage points in the past decade. With the increase in life expectancy and the overlapping effect of China's family planning policy, the dependency ratio of the elderly has increased sharply. According to the National Bureau of Statistics, China's old-age dependency ratio was $11.6 \%$ in 2009 but increased to $16.8 \%$ in 2018. The number of people over 65 years of age has increased by 53.51 million from 2009 to 2018. The Development Research Center of the State Council predicts that the proportion of people over 60 years will exceed $20 \%$ of the total population by 2025 . The sharp increase in the old-age dependency ratio has placed tremendous pressure on the income and expenditures of China's basic pension insurance fund. By 2018, the fund income of China's Employees Basic Pension System (CEBPS) had increased 3.08 times, and fund expenditure increased 3.83 times, in the previous decade. The rapid increase in the old-age dependency ratio caused the growth rate of fund expenditure to exceed that of fund income, resulting in a fund gap. Without considering central fiscal subsidies, the 
current fund gap in 2018 reached RMB 414.74 billion. According to the "China Pension Actuarial Report 2019-2050", with the change from nearly two payers supporting a retiree in 2019 to almost one payer supporting a retiree in 2050, the sustainability of the CEBPS fund will be greatly impacted.

Because of its public attribute, it is inherently reasonable for public finance to subsidize the fund gap of CEBPS. The government's social security responsibility is the product of historical changes and social progress. The basic pension insurance system aims to share the risks of the whole population and guarantee a basic living standard for the people; the government has an inescapable responsibility for this. A. C. Pigou, the founder of welfare economics, believed that socio-economic welfare depends not only on the total national income, but also on the distribution of social income. The more equal the distribution of social income, the greater the socio-economic welfare. A basic pension insurance system is one means of government redistribution. The government's intervention in the operation and investments of the basic pension insurance fund, including the use of state revenue to subsidize the fund gap, can give full play to the redistribution function of pension insurance and increase socio-economic welfare. Therefore, the consensus of researchers is that the state should subsidize the pension insurance fund with fiscal revenue [6-8]. In fact, the National Development and Reform Commission (NDRC) (2000) No. 8 document issued specific instructions on the timely and full payment of basic pension and fiscal subsidies for retired employees. In action, according to "Statistical Bulletin on the Development of Human Resources and Social Security", local governments subsidized the fund of CEBPS by RMB 164.6 billion in 2009; in 2017, the figure reached RMB 800.4 billion, an average annual increase of $54 \%$.

"Fiscal risk" is defined as a source of financial stress that could face a government in the future [9]. As an important means of macro-control, changes in fiscal revenue and expenditure and their risks are important issues for the government to consider when it regulates the economy and formulates policies. If the income and expenditure gap of China's basic pension insurance fund can be accurately predicted and measured, then the annual fiscal subsidy can be determined, so the government can prepare in advance and avoid fiscal risk. However, many risks lead to fluctuations in the income and expenditure gap. Many researchers have used the absolute index and scenario analysis methods to analyze the fiscal risk of CEBPS in China, but these methods do not consider the adverse impact of risk factors and the probability of adverse changes. Risk factors (for example, longevity risk) lead to the fluctuation of the fund gap. If the government withdraws only the expected gap, when the worst situation occurs within a given confidence level, it will lead to a financial crisis due to insufficient provision to resist fund imbalance. That is, fiscal risk results when the actual gap is greater than the expected gap. Therefore, in this paper, we focus on the most important longevity risk and discuss the fiscal risk of the basic pension insurance system under longevity risk.

With regard to the fiscal risk of the basic pension insurance system, there are two frequently used indicators: the income and expenditure gap of the pension insurance fund and implicit debt. From the perspective of financial balance, it is more important to calculate the flow-based annual pension gap. The cash-flow model based on demographics, economics, and pension systems is commonly used in quantitative measurement. According to the different assignment methods of input variables, cash-flow models are generally divided into three types: deterministic models, stochastic models, and micro-simulation models [10]. It is widely known that the United States is at the forefront of the world in the use of stochastic models in projecting the balance of social security funds. The Office of the Chief Actuary (OCA) has introduced a stochastic prediction model (the OCA Stochastic Model, OSM for short). Meanwhile, the Congressional Budget Office has built a longterm micro-simulation model of social security funds based on individual longitudinal historical data since 2002 [11]. Most studies in other countries have adopted deterministic prediction cash-flow models, while some have begun to establish stochastic forecasting models. Blake and Mayhew [1] focused on the sustainability of the UK state pension 
system in light of population ageing and declining fertility by using a simple model and assessed the consequences of six scenarios involving different possible assumptions about productivity growth, activity rates, and different policy responses. Metzger [12] analyzed the medium-term sustainability of the Swiss old-age pension scheme (AHV) by estimating a "Swedish" actuarial balance sheet, which compared pension liabilities with the explicit and implicit assets of the pension scheme. Belolipetskii and Lepskaya [13] considered the probability of ruin of a pension fund on a finite time interval based on the standard Cramer-Lundberg model, which was modified by specifying enrolment and contribution parameters in the form of random variables. Sonsbeek [3] used a dynamic micro-simulation model for calculating the financial and economic implications of the ageing problem and the policy measures considered based on micro-datasets of all Dutch pensions and pension entitlements in the Netherlands. With population ageing becoming a world-wide trend, longevity risk has been a concern. Mortality models play a basic role in the evaluation of longevity risk. The classic model is the Lee-Carter model [14,15], which is very influential because of its simplicity and high accuracy. In addition, the age-period-cohort model (APC model) and the Cairns-Blake-Dowd model (CBD model) are often used in related research $[16,17]$. Their performance strongly depends on the different patterns shown by mortality data in different countries [18].

Regarding the pension gap of the Chinese system, most researchers have adopted deterministic prediction cash-flow models. For example, Jing et al. [19] constructed an actuarial model to analyze the financial imbalance risk of contribution rate reduction in several scenarios and to investigate the possibility of further reducing the contribution rate. Many studies have used actuarial models to evaluate the financial sustainability of CEBPS under the existing policy scenario and several sets of hypothetical policy scenarios [20-22]. Very few studies have built stochastic prediction models. Tian and Zhao [23] adopted time series modeling techniques to estimate the mortality rate and the fertility rate, focused on the stochastic forecast of the financial sustainability of basic pension. The results showed that an imbalance of the basic pension will occur in 2026. Chen and Yang [24] explored the financial self-balancing ability of the individual accounts of CEBPS. In the particularly serious scenario that the individual accounts' previous accumulated funds are zero, the bookkeeping rate and the investment return rate are considered as stochastic variables. Some studies have considered the impact of longevity risk. Xie et al. [25] aimed to investigate the impact of China's new fertility policy on the actuarial balance of its CEBPS fund, with a stochastic mortality model included to address longevity risk. Zhao et al. [26] built a comprehensive risk assessment system to evaluate the solvency sustainability of CEBPS by integrating the Lee-Carter model into their population projection.

The existing literature includes a considerable amount of research on the operation and fiscal risk of CEBPS in China, but there is room for improvement. First, when considering the fiscal risk of CEBPS, the existing literature does not describe all cash flows according to the social security system. For example, when calculating the expenditure of the basic pension insurance fund, in addition to the basic pension, funeral expenses and individual account balances should also be considered. The payment and distribution methods of the insured have policy provisions, and cash flow should be calculated according to the policy. Moreover, the income and expenditure model does not take a person as the basic unit for more accurate calculation. Second, most researchers still use the income and expenditure gap to measure and analyze the fiscal risk of China's basic pension insurance system. To introduce more general risk measurement methods (e.g., the unconditional variance method or the value-at-risk (VaR) method) into the research, it is important to put forward more precise and targeted measures to prevent fiscal risk in the pension insurance system.

Based on the existing problems, in this paper, we first predicted the dynamic mortality rate by age and gender based on the Lee-Carter model and the data from the "China Statistical Yearbook". Second, we established a model for the income and expenditure of CEBPS according to the actuarial balance principle in combination with the actual payment and distribution method in China. Then we predicted the dynamic and random future 
changes in the income and expenditure gap of CEBPS by using actual data from China and analyzed the sustainability of the pension insurance. Finally, we used risk measurement methods (including the unconditional variance method, the value-at-risk (VaR) method, and others) to discuss fiscal risk and conduct a sensitivity analysis.

The paper is organized as follows: Section 2 describes an actuarial model of basic pension insurance; Section 3 includes the dynamic mortality prediction and parameter calibration; Section 4 provides a fiscal risk assessment of CEBPS under longevity risk; and Section 5 summarizes the research.

\section{Actuarial Model of Basic Pension Insurance}

We established a prediction model for the income and expenditure of CEBPS with dynamic mortality to measure the fiscal risk caused by longevity risk and provide policy basis for the government.

\subsection{Dynamic Mortality Model}

By introducing time and age factors and a random disturbance term into the LeeCarter model [14,15], it has been shown possible to achieve high goodness-of-fit for mortality prediction in many countries. Although the prediction effect of the model on limited data needs to be improved, considering the complexity of the improved Lee-Carter model and the sufficient data in our study, and after comparing multiple dynamic mortality models, we considered the Lee-Carter model to be effective for fitting the data of China's population mortality. Therefore, we used the classic Lee-Carter model to build a dynamic model of China's mortality by gender and age. The expression of the Lee-Carter model based on single-age mortality data is as follows:

$$
\ln \left(m_{x, t}\right)=\alpha_{x}+\beta_{x} k_{t}+\varepsilon_{x, t}
$$

where $m_{x, t}$ is the central mortality rate at $x$ years old in year $t ; \alpha_{x}$ is the average level of logarithmic central mortality rate at $x$ years old, $\beta_{x}$ is the age factor (these two parameters are only related to age); $k_{t}$ is the time factor, which indicates the change in mortality rate with time; and $\varepsilon_{x, t}$ is the random error term of normal distribution. The least square method and weighted least square method were used to estimate the parameters. First, the ordinary least squares method (OLS) was used to obtain the following results:

$$
\min \sum_{x=0}^{N} \sum_{t=1}^{T}\left(\ln \left(m_{x, t}\right)-\alpha_{x}-\beta_{x} k_{t}\right)^{2}
$$

Under the boundary condition $\sum_{x=0}^{N} \beta_{x}=1, \sum_{t=1}^{T} k_{t}=0$, we obtained the unique solution of the parameter $\alpha_{x}$ :

$$
\hat{\alpha_{x}}=\frac{\sum_{t=1}^{T} \ln \left(m_{x, t}\right)}{T}, x=0,1,2, \ldots \ldots, N
$$

The estimation methods for Lee-Carter model parameters include matrix singular value decomposition (SVD), OLS, and weighted least square (WLS). The SVD and OLS methods give the same weight to the mortality of different age groups. Many researchers have shown that different age groups have large differences in population size and numbers of deaths [27], so the WLS method was better than the SVD and OLS methods. The WLS method estimates the parameters $k_{t}$ and $\beta_{x}$ of the Lee-Carter model through the following two steps. 
The first step is to sum the left and right sides of Equation (1) for all $x$ under condition $\sum_{x=0}^{N} \varepsilon_{x, t}=0$ :

$$
\hat{k_{t}}=\sum_{x=0}^{N}\left(\ln \left(m_{x, t}\right)-\hat{\alpha_{x}}\right)
$$

In the second step, the variance proved by Wilmoth [28] is approximately equal to the reciprocal of the death toll, so it can be used as the weight of the sum of squares of the residuals. By minimizing the sum of the squares of the weighted residuals, the following results are obtained:

$$
\min \sum_{x=0}^{N} \sum_{t=1}^{T} d_{x, t}\left(\ln \left(m_{x, t}\right)-\hat{\alpha}_{x}-\beta_{x} \hat{k}_{t}\right)^{2}
$$

Taking the derivative and setting the derivative to zero, we have

$$
\hat{\beta_{x}}=\sum_{t=1}^{T} d_{x, t} k_{t}\left(\ln \left(m_{x, t}\right)-\hat{\alpha_{x}}\right) / \sum_{t=1}^{T} d_{x, t} k_{t}^{2}
$$

To predict the dynamic change of mortality, it was necessary to predict the time factor $k_{t}$. It could be estimated using the differential autoregressive moving average model ARIMA (p, d, q). Generally, establishing the ARIMA (p, d, q) model requires several steps, including data stabilization, ARIMA model parameter selection, parameter estimation, model applicability test and optimization, and sequence prediction, to predict the future $k_{T+t}$. Central mortality can be calculated according to $m_{T+t}=\exp \left(\hat{\alpha_{x}}+\hat{\beta_{x}} \hat{k_{t}}+\right.$ $\left.\varepsilon_{x, T+t}\right)$. Assuming that the mortality rate follows an exponential distribution, we have $m_{x, T+t}=\mu_{x, T+t}=-\ln \left(1-q_{x, T+t}\right)$, where $q_{x, T+t}=1-\exp \left(-m_{x, T+t}\right)$. The disturbance term $\varepsilon_{x, T+t}$ follows a normal distribution with a mean value of zero and variance of $\sigma^{2}$. The estimated variance value can be estimated by the sample variance. The confidence interval of mortality can be obtained by Monte Carlo simulation.

\subsection{Income Model}

Referring to Liao [29], and taking the current moment as the zero moment, the income cash flow of the public account $S A$ and individual account $P A$ of CEBPS in period $t(t \geq 1)$ are

$$
\begin{aligned}
& S A^{t}=\sum_{x=\underline{x}}^{\bar{x}} \eta \mathrm{B}_{x+t}^{t} \cdot L W_{x} \cdot{ }_{t} p_{x} \cdot g_{x+t}^{t}+\sum_{s=1}^{t} \eta \mathrm{B}_{c+t-s}^{t} \cdot N L W_{c}(s) \cdot{ }_{t-s} p_{c} \cdot g_{c+t-s}^{t} \\
& P A^{t}=\sum_{x=\underline{x}}^{\bar{x}} \tau \mathrm{B}_{x+t}^{t} \cdot L W_{x} \cdot{ }_{t} p_{x} \cdot g_{x+t}^{t}+\sum_{s=1}^{t} \tau \mathrm{B}_{c+t-s}^{t} \cdot N L W_{c}(s) \cdot{ }_{t-s} p_{c} \cdot g_{c+t-s}^{t}
\end{aligned}
$$

where $\underline{x}$ and $\bar{x}$, respectively, indicate the minimum age and maximum age of employees participating in CEBPS; $\mathrm{B}_{x+t}^{t}$ represents the payment wage base of employees aged $x+t$ in period $t ; L W_{x}$ is the number of employees aged $x$ at zero moment; $N L W_{c}(s)$ is the number of new insured persons aged $c$ in period $s ; \eta$ and $\tau$, respectively, represent the enterprise contribution rate and the individual contribution rate; and $g_{x+t}^{t}$ is the payment persistence rate of employees aged $x+t$ in period $t$. The survival probability $p_{x}$ and ${ }_{t-s} p_{c}$ are determined using Formula (1).

\subsection{Expenditure Model}

The fund expenditure of CEBPS is divided into three parts: expenditure of retired staff, expenditure of on-the-job employees, and expenditure of the newly insured among on-the-job employees. The survival probability and death probability used in the three parts of the expenditure were determined by Formula (1). 


\subsubsection{Expenditure Model of Retired Staff}

At zero moment, the expenditures of the public account $B P R$ and individual account $P P R$ of CEBPS to retired staff in period $t(t \geq 1)$ are, respectively,

$$
\begin{gathered}
B P R^{t}=\sum_{y=\underline{y}}^{\bar{y}} L R_{y}\left\{{ }_{t} p_{y} \cdot B P_{y} \cdot \prod_{k=1}^{t}\left(1+\alpha_{k}\right)+{ }_{t-1} p_{y} \cdot q_{y+t-1} \cdot D \cdot \prod_{k=1}^{t}\left(1+\beta_{k}\right)+{ }_{t} p_{y} \cdot P P_{y} I_{\left(t+y-t^{r} \geq h\right)}\right\} \\
P P R^{t}=\sum_{y=\underline{y}}^{\bar{y}} L R_{y}\left\{{ }_{t} p_{y} \cdot P P_{y}\left[1-I_{\left(t+y-t^{r} \geq h\right)}\right]+{ }_{t-1} p_{y} \cdot q_{y+t-1} \cdot P P_{y} \max \left[h-\left(t+y-t^{r}\right), 0\right]\right\}
\end{gathered}
$$

where $y$ and $\bar{y}$ represent the minimum and maximum age of the employees in the retirement pool, respectively; $L R_{y}$ is the number of insured retirees aged $y$ at zero moment; $h$ is the divisor factor of the retirees aged $t^{r}$ (the divisor factor is defined as the number of planned payment months during the payment period of pension insurance benefits, and is measured in years here); $B P_{y}$ is the average basic pension level of retirees aged $y$ at zero moment; $\alpha_{t}$ is the average growth rate of basic pension in year $t ; D$ is the funeral expenses in period 0 ; $\beta_{t}$ is the average growth rate of funeral expenses in year $t$; and $P P_{y}$ is the average pension level of the personal account of $(y)$ at zero moment. When the number of receiving months of pension in individual account exceeds the number of planned payment months, the value of the indicative function $I_{\left(t+y-t^{r} \geq h\right)}$ is 1 ; otherwise, it is 0 .

\subsubsection{Expenditure Model of On-the-Job Employees}

Taking the current moment as the zero moment, we have

$$
B P W^{t}=\sum_{x=\underline{x}}^{\bar{x}} L W_{x} \cdot\left\{{ }_{t} p_{x} \cdot\left[1-I_{\left(t<t^{r}-x\right)}\right] B P W_{x}^{t}+{ }_{t-1} p_{x} q_{x+t-1} \cdot D \prod_{k=1}^{t}\left(1+\beta_{k}\right)\right\}
$$

$P P W^{t}=\sum_{x=\underline{x}}^{\bar{x}} L W_{x}\left\{{ }_{t} p_{x} \cdot\left[1-I_{\left(t<t^{r}-x\right)}\right] \cdot P P W_{x}^{t}+_{t-1} p_{x} q_{x+t-1} \cdot\left[1-I_{\left(t<t^{r}-x\right)}\right] \cdot P A S_{x}^{t}+_{t-1} p_{x} q_{x+t-1} \cdot I_{\left(t<t^{r}-x\right)} \cdot P A_{x}^{t}\right\}$

$$
\begin{gathered}
B P W_{x}^{t}=B P_{x}^{t^{r}} \prod_{k=t^{r}-x}^{t}\left(1+\alpha_{k}\right)+P P_{x}^{t^{r}} I_{\left(t-t^{r}+x \geq h\right)} \\
B P_{x}^{t^{r}}=\bar{W}^{t^{r}-x-1} \cdot Z_{x}^{e q u} \cdot N_{x}^{e q u} \cdot 1.2 \%+0.005 T^{\prime}\left(\bar{W}^{t^{r}-x-1}+\bar{W}^{t^{r}-x-1} \cdot I X\right) \\
P P W_{x}^{t}=P P_{x}^{t^{r}} \cdot\left[1-I_{\left(t-t^{r}+x \geq h\right)}\right] \\
P P_{x}^{t^{r}}=\frac{\sum_{k=0}^{t^{r}-x} \eta B_{x+k}^{k} \cdot(1+r)^{t^{r}-k-x}+P A Y_{x} \cdot(1+r)^{t^{r}-k-x}}{h} \\
P A S_{x}^{t}=P P W_{x}^{t} \max \left\{h-\left(t+x-t^{r}\right), 0\right\} \\
P A_{x}^{t}=\sum_{k=0}^{t} \eta B_{x+k}^{k}(1+r)^{t-k}+P A Y_{x}(1+r)^{t}
\end{gathered}
$$

where $B P W^{t}$ and $P P W^{t}$ are, respectively, the expenditures of the public account and the individual account of CEBPS to on-the-job employees in period $t(t \geq 1) ; B P W_{x}^{t}$ and $P P W_{x}^{t}$ are, respectively, the pension level of the public account and the pension level of the individual account of on-the-job employees aged $x$ at the time $t ; t^{r}$ is the retirement age of on-the-job employees; $B P_{x}^{t^{r}}$ is the initial basic pension level of $x$-year-old employees after retirement at $t^{r}$ years old; $Z_{x}^{\text {equ }}$ and $N_{x}^{\text {equ }}$ are the deemed contribution index and the deemed contribution period corresponding to the transitional pension; IX is the average contribution index of on-the-job employees; $P A S_{x}^{t}$ is the balance of individual account of on-the-job employees aged $x$ at the time $t ; P A Y_{x}$ is the existing accumulated amount of 
individual account of on-the-job employees aged $x$ at zero moment; and $P A_{x}^{t}$ is the existing accumulated amount of individual account of on-the-job employees aged $x$ at the time $t$.

\subsubsection{Expenditure Model of New Insured On-the-Job Employees}

Taking the current moment as the zero moment, the expenditures of the public account and individual account of CEBPS to new insured on-the-job employees in period $t(t \geq 1)$ are, respectively,

$$
\begin{aligned}
& B P N^{t}=\sum_{s=1}^{t} N L W_{c}(s)\left\{{ }_{t-s} p_{c} \cdot\left[1-I_{(t<r)}\right] B P W_{c}^{t}(s)+_{t-s-1} p_{c} q_{c+t-s-1} \cdot \mathrm{D} \prod_{k=1}^{t}\left(1+\beta_{k}\right)\right\} \\
& P P N^{t}=\sum_{s=1}^{t} N L W_{c}(s) \cdot\left\{{ }_{t-s} p_{c} \cdot\left[1-I_{(t<r)}\right] \cdot P P W_{c}^{t}(s)+_{t-s-1} p_{c} q_{c+t-s-1} \cdot\left[1-I_{(t<r)}\right] \cdot P A S_{c}^{t}(s)\right. \\
& \left.+_{t-s-1} p_{c} q_{c+t-s-1} \cdot I_{(t<r)} \cdot P A_{c}^{t}(s)\right\} \\
& B P W_{c}^{t}(s)=B P W_{c}^{r}(s) \prod_{k=r}^{t}\left(1+\alpha_{k}\right)+P P W_{c}^{r}(s) I_{(t \geq r+h))} \\
& B P W_{c}^{r}=\frac{1}{2}\left(\bar{W}^{r-1}+\bar{W}^{r-1} \cdot E Z_{\mathrm{c}}^{r}(s)\right) \cdot E N_{c}^{r}(s) \cdot 1 \% \\
& P P W_{c}^{t}(s)=P P W_{c}^{r}(s) \cdot\left[1-I_{(t \geq r+h)}\right] \\
& P P W_{c}^{r}=\frac{\sum_{k=s}^{r} \tau B_{c+k}^{k} \cdot(1+r)^{r-k}}{h} \\
& P A S_{\mathrm{C}}^{t}(s)=P P W_{c}^{t}(s) \max \{h-(t-r), 0\}
\end{aligned}
$$

where $s(0 \leq s \leq t)$ and $c$ are the time and age of the new insured employees entering the insurance system for the first time; the corresponding retirement time of this group is $r=s+t^{r}-c ; E Z_{\mathrm{c}}^{r}(s)$ is the expected contribution index of $c$ participating in insurance at time $s$ and retiring at time $r$; and $E N_{\mathrm{c}}^{r}(s)$ is the expected payment period of $c$ participating in insurance at time $s$ and retiring at time $r$.

\section{Mortality Prediction and Parameter Calibration}

\subsection{Mortality Prediction}

\subsubsection{Revision and Supplement of Mortality Data}

In the "China Population and Employment Statistical Yearbook", except for the data obtained from the census in 1990, 2000, and 2010, all data is sampling data. The sampling data for each year is not fixed, and sampling frequency is random. In 1995, 2005, and 2015 , about $1 \%$ of the population was sampled, whereas sampling data in other years was about $0.1 \%$ of the total population. To facilitate estimation and analysis, we adopted $1 \%$ sampling. The small sampling base can result in a lack of death population in some age groups, which is inconsistent with reality. For this type of abnormal data, we can use the linear interpolation method to correct the data. The formula is as follows:

$$
\ln \left(m_{x, t}\right)=\frac{1}{T_{2}-T_{1}} \times\left[\left(T_{2}-t\right) \ln \left(m_{x, T_{1}}\right)+\left(t-T_{1}\right) \ln \left(m_{x, T_{2}}\right)\right]
$$

where $T_{1}$ and $T_{2}$ are relatively reliable adjacent statistical years. For example, the data for 1996 are missing, but we can use data of 1995 and 2000 for linear interpolation.

In addition to the problem of abnormal data, the data provided by the "China Population and Employment Statistical Yearbook" also has the problem of deletion of high-age mortality data, so it is necessary to extrapolate the mortality of the elderly population. Because there are few elderly people over 100 years old, the mortality rate used in this paper is accurate to 100 years old. For the different lengths of statistical data and the lack of 
high age population data, we used the Coale-Kisker (C-K) model to expand the mortality rate. The expression of the improved $\mathrm{C}-\mathrm{K}$ model is as follows:

$$
\ln \left(m_{x}\right)=a+b x+c x^{2}+\varepsilon
$$

The values of parameters $a, b$, and $c$ are estimated by the least squares method. According to the above formula, we can expand the mortality rates of men and women aged 90 to 99 from 1994 to 2017. The results are shown in Figures 1 and 2, where it can be seen that mortality at the same age is decreasing year by year, and the greater the age, the higher the mortality, which is in line with the actual situation.

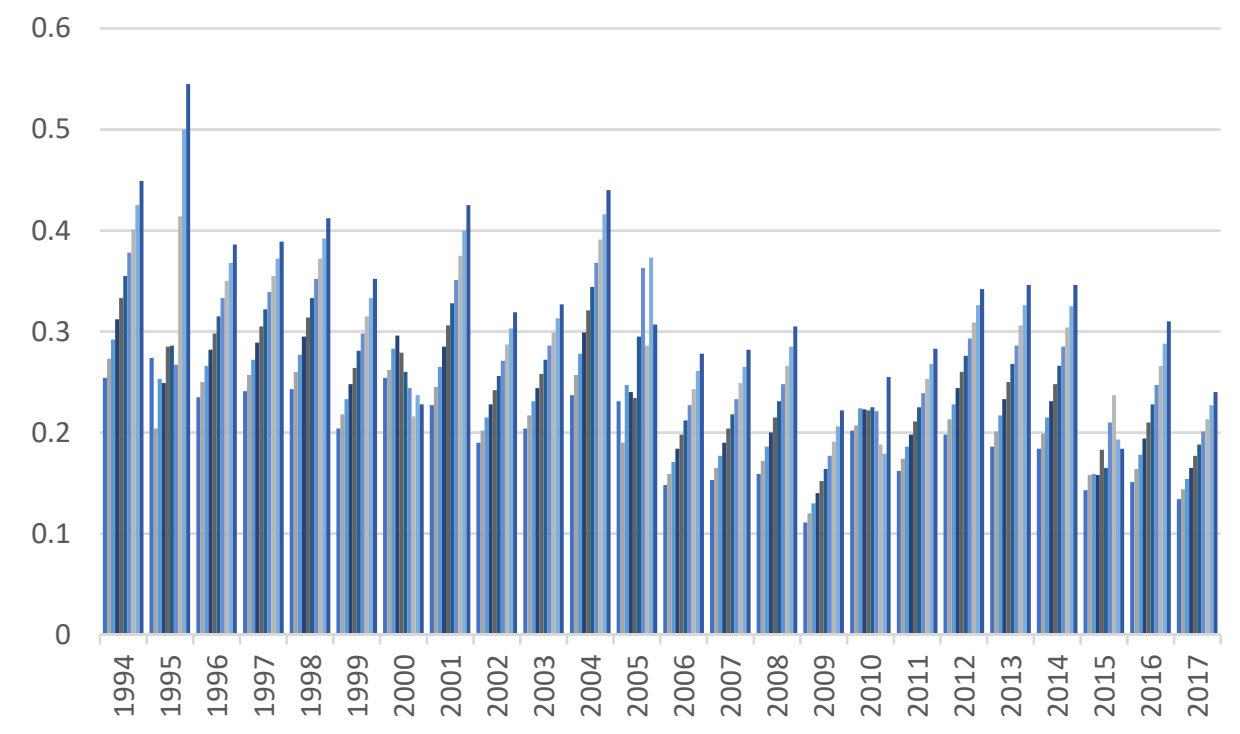

Figure 1. Expanded chart of mortality rates of men aged 90 to 99 from 1994 to 2017 by using the improved Coale-Kisker model.

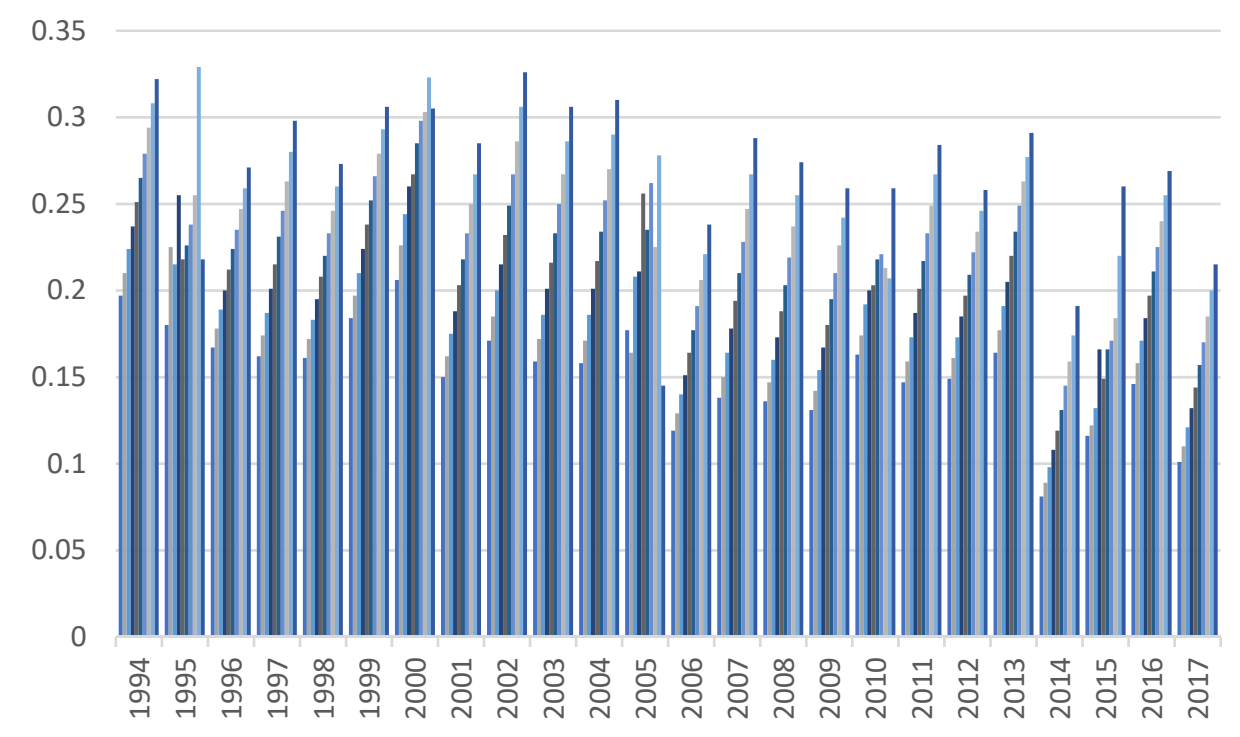

Figure 2. Expanded chart of mortality rates of women aged 90 to 99 from 1994 to 2017 by using the improved Coale-Kisker model.

\subsubsection{The Lee-Carter Model and Prediction of Mortality}

Based on mortality of the elderly and the correction of abnormal data obtained in the previous section, we obtained relatively complete mortality data for all age groups 
from 1994 to 2017. Using these data, and with the help of the OLS and WLS methods, we estimated the parameters $\alpha_{x}, \beta_{x}$, and $k_{t}$. The estimated values of parameters $\alpha_{x}$ and $\beta_{x}$ are given in Appendix A, and the estimated value of time factor $k_{t}$ from 1994 to 2017 is given in Appendix B.

Using the estimated data, we needed to predict parameter $k_{t}$, which was the key to using the Lee-Carter model to fit and predict mortality. We used the ARIMA (p, d, q) model to fit and created a trend chart of male and female time factors $k_{t}$ based on the estimated data. In Figure 3, we can see that both male and female time factors $k_{t}$ show an obvious downward trend with the passage of time, and that values turn from positive to negative. Reasonable values of the ARIMA model parameters $p, d$, and $q$ can be obtained through several steps, such as stationary processing, ARMA model selection, parameter estimation, model applicability test and optimization, or sequence prediction.

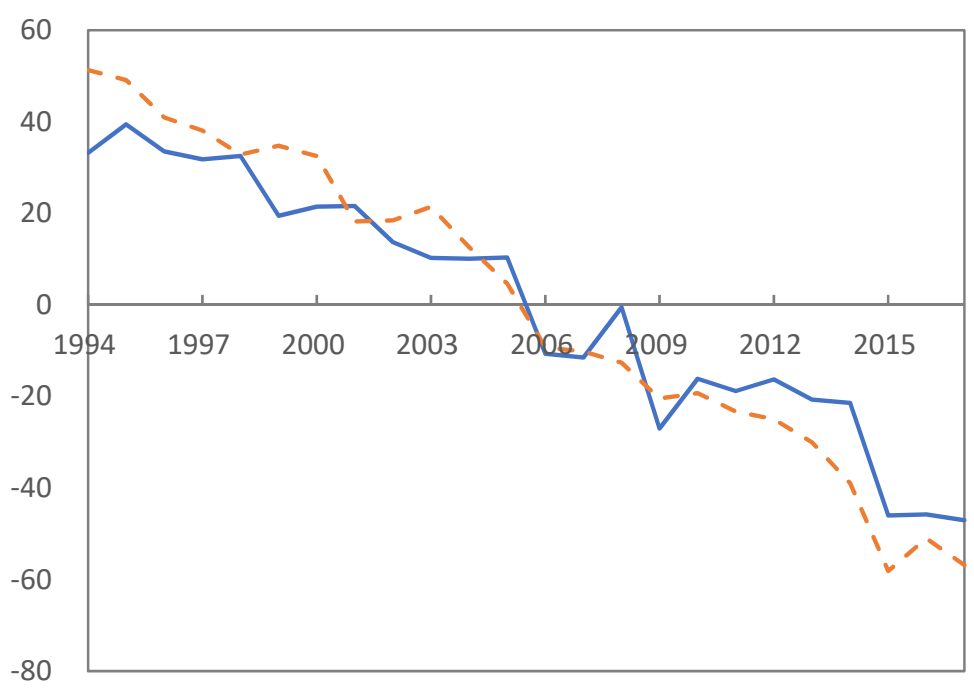

Figure 3. Trend chart of male (solid line) and female (dashed line) time factors $k_{t}$ from 1994 to 2017.

Because of space limitations, the steps of parameter estimation and applicability test of the ARIMA (p, d, q) model are given in Appendix C. But through the applicability test, we believe that the male sequence $k_{t}$ belongs to the ARIMA $(0,1,1)$ model, which extracts sufficient information. The specific form of the ARIMA $(0,1,1)$ model in accordance with the male sequence $k_{t}$ is as follows:

$$
k_{t}=k_{t-1}-3.8891-0.9643 \varepsilon_{t-1}+\varepsilon_{t}
$$

The female sequence $k_{t}$ also belongs to the ARIMA $(0,1,1)$ model. The specific form of ARIMA $(0,1,1)$ model in accordance with female sequence $k_{t}$ is as follows:

$$
k_{t}=k_{t-1}-4.9166-0.9997 \varepsilon_{t-1}+\varepsilon_{t}
$$

According to the specific formulas of the ARIMA model, we can predict future values of male and female time factors $k_{t}$. The predicted values for the next 50 years are given in Appendix D.

\subsubsection{Validity Test of the Lee-Carter Model}

We selected the latest available data in 2017 to compare the mortality rates of men and women in all age groups with those predicted by the Lee-Carter model, as shown in Figures 4 and 5. Figure 4 indicates that the curves of actual and predicted values of male mortality in 2017 almost coincide, indicating that the fitting of the Lee-Carter model to predict male mortality in China is close to ideal. Figure 5 indicates that the fitting effect of actual and predicted values of female mortality is very good until the age of 88 . After 
this point, the predicted value of mortality is slightly higher than the real value, but the difference is small and within the acceptable range.

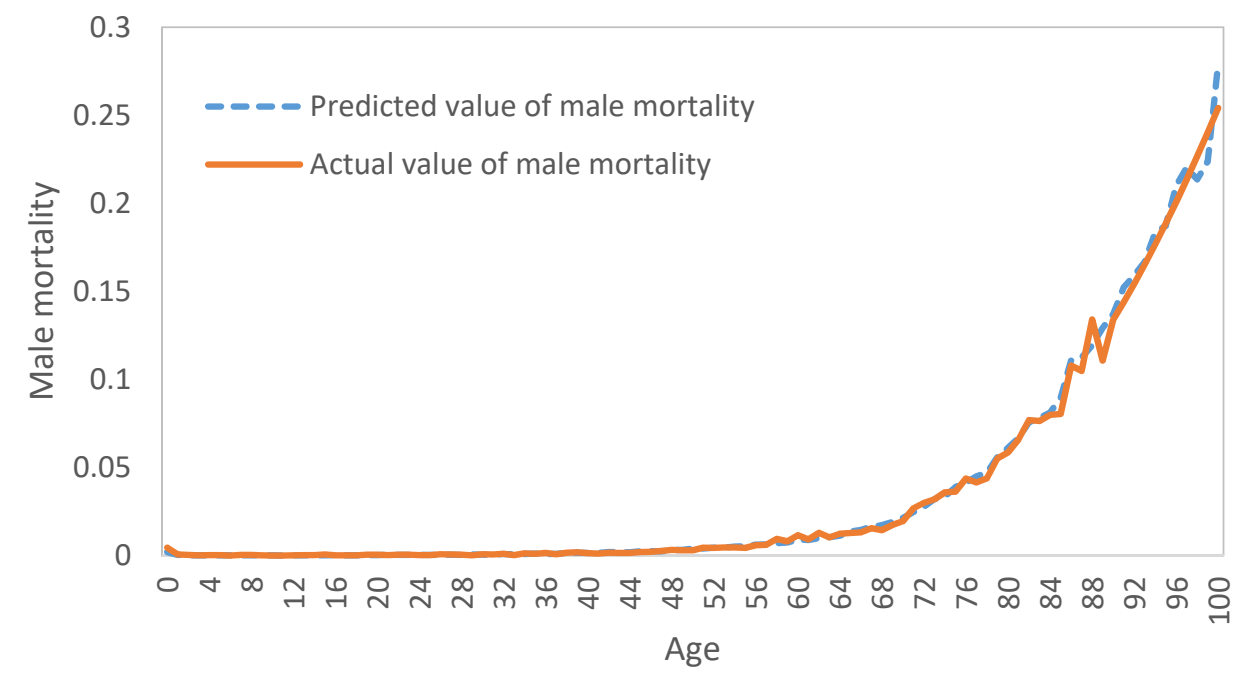

Figure 4. Comparison of actual (solid line) and predicted (dashed line) male mortality in 2017.

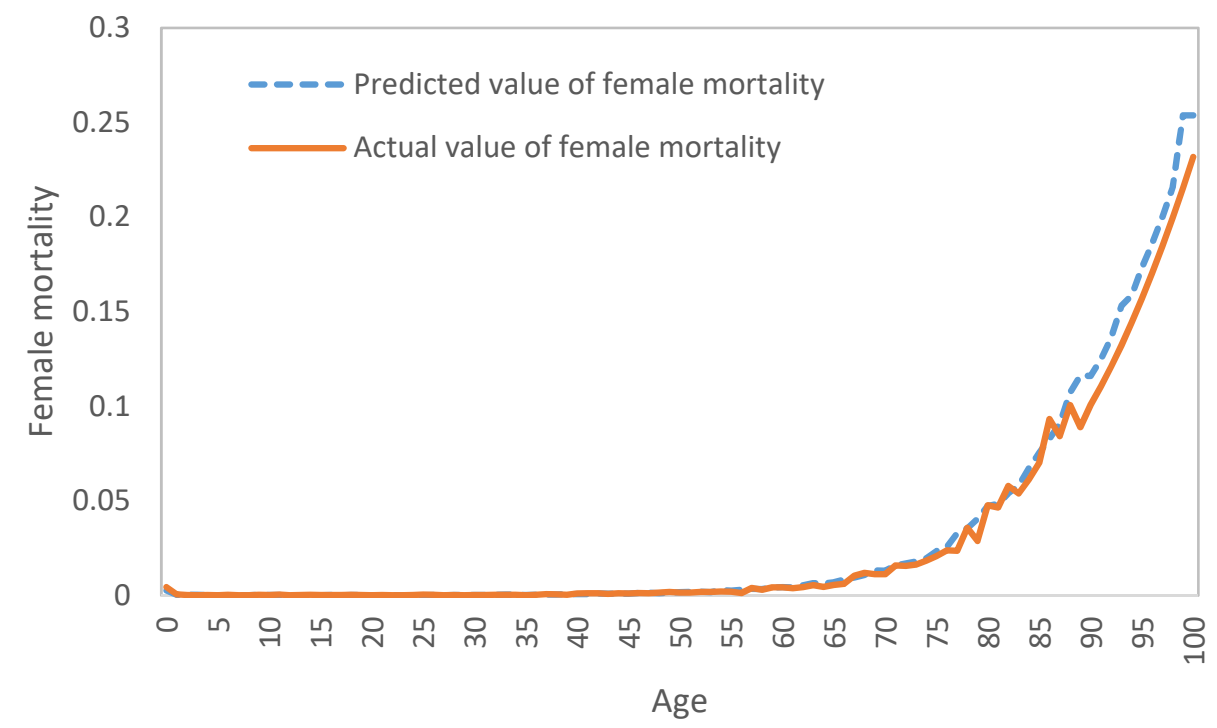

Figure 5. Comparison of actual (solid line) and predicted (dashed line) female mortality in 2017.

\subsection{Parameter Setting and Basis}

\subsubsection{Future Population Structure}

The future population structure can be determined by the existing population structure, future mortality, and future birth rate.

- Existing population structure. The proportion of the population of each age was obtained from "China Population and Employment Statistical Yearbook 2010" and was used as the initial population structure of the model.

- Future mortality. According to the Lee-Carter model, we obtained 10,000 samples of mortality in each age every year and used the expected value of the sample to represent mortality at each age.

- Future birth rate. Many researchers believed that implementation of the two-child policy would result in a short-term increase in China's birth rate. However, due to the lag of policy and contemporary youth's fear of marriage and childbirth, China's fertility rate has not increased significantly in recent years. The National Bureau of 
Statistics announced that the fertility rate in 2018 was only 1.094, the lowest value on record. In this paper, we assumed that the effect of the two-child policy is not obvious and took the average fertility rate of women of childbearing age in 2014 and 2015 as the corresponding fertility rate (the National Bureau of Statistics has only published the fertility rate of women of childbearing age in 2015 and before) to calculate the birth rate.

\subsubsection{Employment and Wage System}

- Human capital parameters. In this paper, we took the average value of human capital parameters calculated by the average wages at every age of Beijing employees participating in CEBPS in 2008 and 2009 as the value of human capital level at every age.

- Wage growth rate. We assumed that the future wage growth rate of enterprise employees was $7.7 \%$ in $2018-2020,6.6 \%$ in $2021-2025$, and $5.7 \%$ in $2026-2068$.

- Unemployment rate (the introduction of unemployment rate was due to the interruption of contributions caused by unemployment, which affects pension income). According to the data released by the National Bureau of Statistics, the unemployment rate in China has been relatively stable since the beginning of this century. It has fluctuated between $3.8 \%$ and $4.3 \%$ from 2002 to 2018 . The average value of the unemployment rate over 17 years is about $4.09 \%$. We assumed that the unemployment rate would remain unchanged at $4.09 \%$ in the future.

- Urbanization rate (the reason for the introduction of urbanization rate is that China's urbanization rate has not yet reached saturation and is growing, which will affect the number of new insured people of CEBPS). According to "National Population Development Plan (2016-2030)", the urbanization rate of China's permanent population will reach $70 \%$ in 2030 , whereas it was $58.52 \%$ in 2018 . Therefore, we predicted that China's urbanization rate would increase by 1\% per year from 2019 to 2030 and would remain unchanged after 2030.

\subsubsection{Basic Pension Insurance System}

- $\quad$ Age parameters. We assumed that urban residents begin work at the age of 21, male employees retire at the age of 60, and female employees retire at the age of 55.

- Contribution rate and divisor factor. According to the "Decision of the State Council on Improving the Basic Pension Insurance System for Enterprise Employees" (NDRC (2005) No. 38), the contribution rate of the individual account is set at $8 \%$, the contribution rate of the public account is set at $20 \%$, the divisor factor (defined as the number of planned payment months during the payment period of pension insurance benefits, here measured in years) of male retirees is 12 years, and the divisor factor of female retirees is 14 years. In 2019, the State Council promulgated "Notice of the General Office of the State Council on Printing and Distributing Comprehensive Plans for Reducing Social Insurance Rates", which indicated that the contribution rate of the public account of CEBPS would be reduced to 16\% from May 1, 2019. Based on the actual situation, the public account contribution rate was calculated as $20 \%$ before May 2019 and 16\% after May 2019.

- Return on investment. Referring to "The Annual Report of the National Social Security Fund Council Fund (2013)", the annual return on investment of the national social security fund since its establishment is $8.13 \%$. Therefore, we assumed that the return on investment of both the pension insurance fund and the personal account would be $8.13 \%$ after 2017.

- Basic pension growth rate. According to urban basic pension insurance data released by the National Bureau of Statistics, the annual growth rate of the per capita basic pension was $10 \%$ from 2006 to 2015. In 2016, the government work report set the growth rate of the basic pension at 6.5\%. It was 5.5\% in 2017 and 5\% in 2018 and 2019. Therefore, the basic pension growth rate was set at $5 \%$. 
- Funeral allowance. Because of the different calculation methods of funeral subsidies in different regions, referring to Liao [29], we assumed that the one-time payment of funeral expenses and pension was $60 \%$ of the average social wage at the time of death.

\subsubsection{Insurance Status}

- Composition of existing insured persons. The "China Labor Statistics Yearbook 2018" shows the number of urban on-the-job employees participating in CEBPS and the number of urban retired employees participating in CEBPS in 2017. Assuming that the proportion of insured people at every age in 2017 is the same as the proportion of the insured people at every age in Beijing in 2008, we calculated the number of the insured people of every age of both on-the-job and retired urban employees in 2017.

- Composition of new insured persons. In 2017, the 21-year-old population as a proportion of the total population was $1.22 \%$. Assuming that it will remain unchanged in future, the size of the 21-year-old population in the future can be calculated, and the product of 21-year-old population, urbanization rate, and labor participation rate can represent the number of new insured people.

\section{Fiscal Risk Assessment of CEBPS under Longevity Risk}

\subsection{Model Validation}

Using actual data from China and the model in this paper, we calculated the average values of income and expenditure of CEBPS from 2009 to 2018 and compared it with actual income and expenditure. The results are shown in Table 1.

Table 1. Income and expenditure of CEBPS from 2009 to 2018 (unit: RMB 100 million) ${ }^{1}$.

\begin{tabular}{ccccccc}
\hline Year & Actual Income & $\begin{array}{c}\text { Estimated } \\
\text { Income }\end{array}$ & $\begin{array}{c}\text { Absolute } \\
\text { Percentage Error of } \\
\text { Income }\end{array}$ & $\begin{array}{c}\text { Actual } \\
\text { Expenditure }\end{array}$ & $\begin{array}{c}\text { Absolute } \\
\text { Estimated } \\
\text { Expenditure }\end{array}$ & $\begin{array}{c}\text { Percentage Error of } \\
\text { Expenditure }\end{array}$ \\
\hline 2009 & 9534 & $10,068.66$ & $5.61 \%$ & 8894.4 & 9735.32 & $9.45 \%$ \\
2010 & 11,110 & $11,765.67$ & $5.90 \%$ & $10,554.9$ & $10,167.91$ & $3.67 \%$ \\
2011 & 13,956 & $13,945.07$ & $0.08 \%$ & $12,765.0$ & $11,174.73$ & $12.46 \%$ \\
2012 & 16,467 & $15,740.66$ & $4.41 \%$ & $15,561.8$ & $15,622.41$ & $0.39 \%$ \\
2013 & 18,634 & $17,547.78$ & $5.83 \%$ & $18,470.4$ & $19,588.41$ & $6.05 \%$ \\
2014 & 20,434 & $22,947.38$ & $12.30 \%$ & $21,754.7$ & $20,762.44$ & $4.56 \%$ \\
2015 & 23,016 & $24,922.45$ & $8.28 \%$ & $25,812.7$ & $26,352.53$ & $2.09 \%$ \\
2016 & 26,768 & $28,013.43$ & $4.65 \%$ & $31,853.8$ & $31,583.61$ & $0.85 \%$ \\
2017 & 33,403 & $30,992.80$ & $7.22 \%$ & $38,051.5$ & $37,338.04$ & $1.87 \%$ \\
2018 & 38,813 & $37,198.93$ & $4.16 \%$ & $42,960.8$ & $41,928.16$ & $2.40 \%$ \\
\hline
\end{tabular}

${ }^{1}$ The data came from "China Labor Statistics Yearbook 2018" and the budget and final accounts of the Ministry of Finance in 2018.

From the perspective of quantitative analysis, we can use the mean absolute percentage error (MAPE) to analyze the effectiveness of the basic pension. The smaller the value of MAPE, the better the fitting effect of income and expenditure. The expression of MAPE is as follows:

$$
\operatorname{MAPE}(\hat{x})=\frac{1}{N} \sum_{i=1}^{N} \frac{\left|x_{i}-\hat{x}_{i}\right|}{x_{i}}
$$

where $N$ is sample size, $x_{i}$ is the actual value, and $\hat{x}_{i}$ is the predicted value. The actual income of the pension insurance fund refers to the actual income collected by the pension insurance fund without the central adjustment fund. According to data in Table 1, the MAPE values of income and expenditure of CEBPS from 2009 to 2018 were $6.03 \%$ and $4.60 \%$, respectively. Referring to a goodness-of-fit measurement standard table, we can see that the actuarial model of basic pension had a good fitting effect. 


\subsection{Fiscal Risk Assessment of CEBPS under Longevity Risk}

\subsubsection{Fluctuation of the Fund Gap under Longevity Risk}

Taking 2017 as the starting year, we calculated the fund operation of CEBPS from 2018 to 2067. Without fiscal subsidies, the results of the average fund gap of CEBPS and its confidence interval are shown in Figure 6.

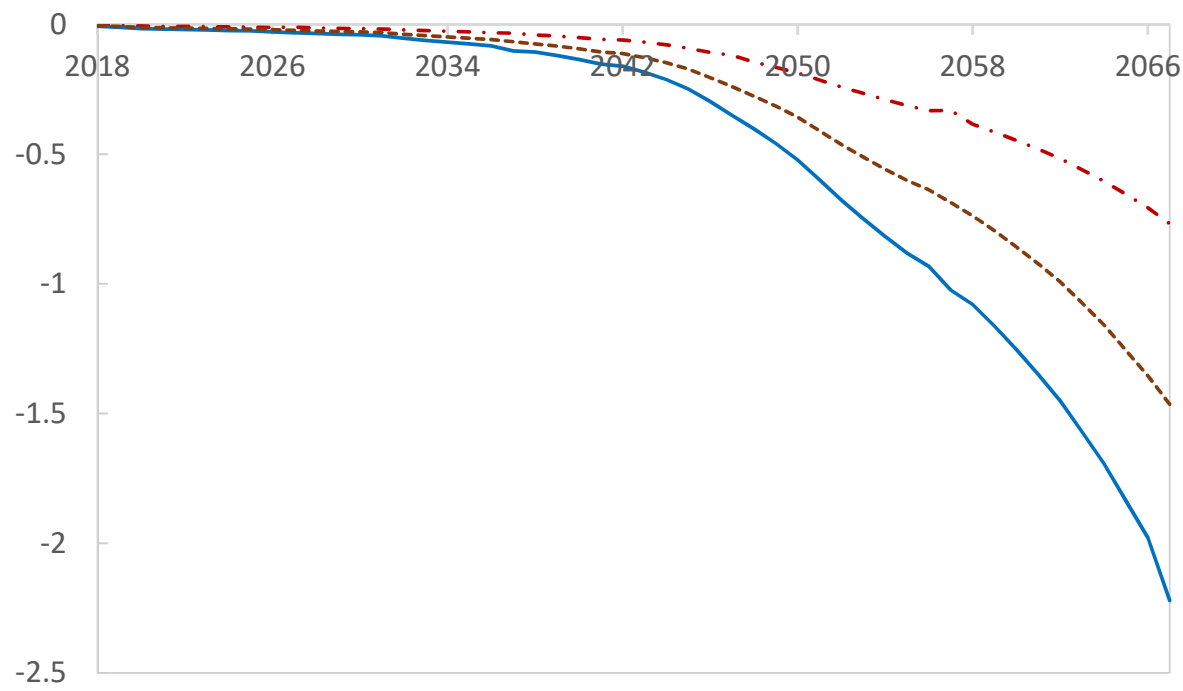

Figure 6. Calculation of the current fund balance of CEBPS (the solid line indicates the current fund balance floor, the dashed line indicates the expected value of the current fund balance, and the dashed-dotted line indicates the current fund balance cap; unit = RMB 100 trillion).

If there is no external financing, there will be a fund gap of CEBPS under longevity risk. According to the budget and final accounts of the pension insurance fund of the Ministry of Finance in 2018, the current balance of the CEBPS fund was negative, and the amount of the fund gap was as high as RMB 414.74 billion, accounting for $2.26 \%$ of fiscal revenue in 2018. There is no doubt that the fund gap will increase fiscal pressure. As can be seen in Figure 6, without changing the existing basic pension insurance policy for urban employees, the $95 \%$ confidence interval value of the current fund balance has been and continues to be negative, and the fund gap extends outward in a trumpet shape. The expected value of the current fund balance tends toward the lower limit of the fund balance year by year, and the curve shows a negative exponential decline. In 2067, the $2.5 \%$ and $97.5 \%$ quantiles of fund balance are 1.52 and 0.44 times the expected value, respectively, which indicates a strong likelihood of fiscal risk.

Many researchers have used the absolute index and scenario analysis methods to analyze the fiscal risk of CEBPS, but these methods do not consider the adverse impact of risk factors and the probability of adverse changes. We used more general risk measurement methods to provide a new perspective for evaluating and managing the fiscal risk of CEBPS. Table 2 shows the fiscal risk assessment of CEBPS in the future using various risk measurement methods.

Table 2. Risk measurement results of fund gap (unit: RMB 100 million).

\begin{tabular}{ccccccc}
\hline Year & Mean & Standard Deviation & Coefficient of Variation & VaR & ES & TVaR \\
\hline 2027 & $22,883.7$ & $140,641.7$ & 6.1 & $35,313.3$ & $34,361.0$ & $722,533.1$ \\
2037 & $66,945.3$ & $755,578.2$ & 11.3 & $99,814.3$ & $96,610.3$ & $2,032,019.4$ \\
2047 & $240,002.1$ & $6,249,071.7$ & 26.0 & $350,758.4$ & $337,653.3$ & $7,103,824.8$ \\
2057 & $686,336.9$ & $40,403,533.2$ & 58.9 & $992,681.7$ & $952,773.2$ & $20,048,146.2$ \\
2067 & $1,464,021.7$ & $196,744,166.8$ & 134.4 & $2,124,397.7$ & $2,038,943.3$ & $42,903,264.3$ \\
\hline
\end{tabular}


From Table 2, it can be seen that the mean value of the fund gap increases in multiples, and the coefficient of variation changes from 6.1 in 2027 to 134.4 in 2067. This volatility in the fund gap increases the possibility that the actual fund gap is higher than the expected fund gap. Under the given $95 \%$ confidence level, the maximum risk value of the fund gap in 2067 is RMB 212,439.77 billion; that is, the government must prepare RMB 212,439.77 billion to guard against fiscal risk of CEBPS in 2067. If the government withdraws only RMB $146,402.17$ billion and the worst situation occurs within a given confidence level, it will lead to a financial crisis due to insufficient provision to resist fund imbalance. The tail risk cannot be ignored. The ES (expected shortfall) and TVaR (tail value-at-risk) values of the fund gap also increase rapidly. On the premise of maintaining the existing CEBPS, the fiscal risk borne by the government is increasing.

In the calculation of the fund gap of CEBPS, various results are presented based on different model settings and different assumptions of demographic, economic and policy parameters $[10,19,21]$, as shown in Table 3. But the basic conclusions are similar: the gap will inevitably exist and remain huge in the long term without policy adjustment and systematic reform. Moreover, we have tested the validity of the model, but previous studies have not, and our results are relatively more reliable. Our results show that the fund gap extends outward in a trumpet shape, which is similar to other studies that also use the Lee-Carter model [26].

Table 3. Comparisons to the results of the previous studies (unit: RMB 100 million).

\begin{tabular}{ccccc}
\hline Year & $\begin{array}{c}\text { This Article } \\
\text { Mean Fund Gap }\end{array}$ & $\begin{array}{c}\text { Median Pension Gap under } \\
\text { Low Mortality Rates [10] }\end{array}$ & $\begin{array}{c}\text { Current Deficits under the } \\
\text { Baseline Scenario [19] }\end{array}$ & $\begin{array}{c}\text { Annual Deficit in } \\
\text { Baseline Scenario [21] }\end{array}$ \\
\hline 2027 & $22,883.7$ & & $54,544.6$ & 86,100 \\
2037 & $66,945.3$ & 15,510 & $131,313.3$ & 214,400 \\
2047 & $240,002.1$ & & $249,426.2$ & 420,200 \\
2057 & $686,336.9$ & $367,640.5$ & 578,900 \\
2067 & $1,464,021.7$ & 33,820 & & 742,300 \\
\hline
\end{tabular}

Note: The data in the previous studies are for 2030, 2040, 2050, 2060, 2070.

\subsubsection{The Knock-On Effect of the Fund Gap under Longevity Risk}

The knock-on effect of the fund gap reflects the fiscal pressure faced by the government in the future and the risk of insufficient preparation for fiscal subsidy. Figure 7 shows the knock-on effect of the fund gap of CEBPS from 2018 to 2067 (with the help of the idea of international financial institutions' solvency capital demand VaR, the knock-on effect of fund gap of CEBPS under longevity risk is defined as the difference between the maximum risk value and the expected value of the fund gap in a given confidence interval. The solvency capital demand $\mathrm{VaR}$ refers to the maximum loss that an asset or portfolio may suffer under a given level of confidence interval. The expression is $\operatorname{VaR}(\mathrm{x} ; p)=F_{\mathrm{x}}^{-1}(p)$, where $F_{X}^{-1}(p)=\inf \left\{x \in R / F_{X}(x) \geq p\right\}$.)

In Figure 7, we can see that the knock-on effect of the current fund gap of CEBPS increases rapidly over time. The knock-on effect of the current fund gap in 2018 is only RMB 223.57 billion, but with the increased life expectancy of the population and the lack of potential energy released by the second-child policy, the knock-on effect of the current fund gap will increase to RMB 64,067.13 billion in 2067, with an annual growth rate of $12.68 \%$. To more directly reflect the systematic impact caused by the knock-on effect of the fund gap in the next 50 years, we discounted the total knock-on effect to 2020 with the present value of RMB 116.73 trillion, which is equivalent to 1.15 times GDP and 4.75 times the state fiscal expenditure in 2020. This indicates that the gap of public fiscal subsidy fund is facing great payment pressure in the future, which is likely to lead to fiscal and political risk. It should be dealt with through corresponding policies. 


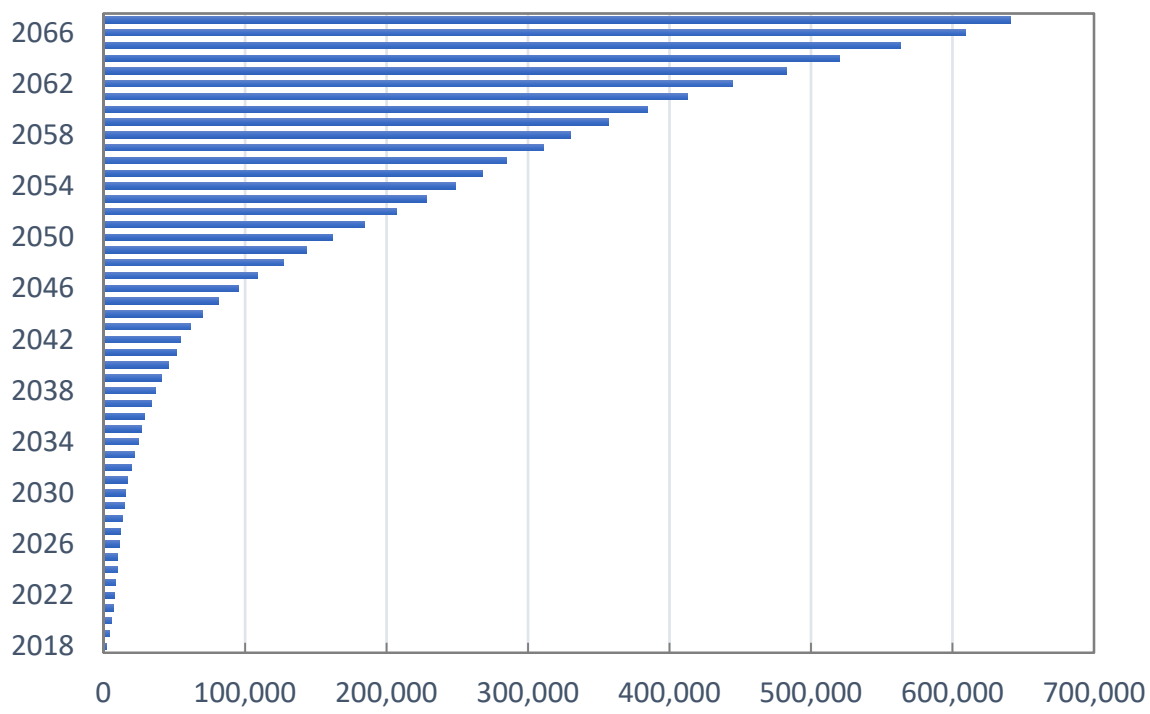

Figure 7. Knock-on effect of current fund gap from 2018 to 2067 (unit: RMB 100 million).

\subsubsection{Sensitivity Analysis of Fiscal Risk of CEBPS}

Measurement of the benchmark situation was based on reasonable assumptions of actual policy and economic factors, but future institutional and economic factors are uncertain, and changes in these factors will affect the measurement result and fiscal risk. Because the fiscal risk of CEBPS is positively related to the knock-on effect of the fund gap, we took the enterprise contribution rate, wage growth rate, urbanization rate, pension growth rate, and age of receiving pension as sensitive factors to analyze their impact on the present value of the total knock-on effect of CEBPS. In a high-speed change scheme, we increased the enterprise contribution rate, wage growth rate, urbanization rate, and basic pension growth rate by $1 \%$ and increased the age of receiving pension by five years. In a low-speed change scheme, we decreased the enterprise contribution rate, wage growth rate, urbanization rate, and basic pension growth rate by $1 \%$ and decreased the age of receiving pension by five years. The results of the sensitivity analysis are shown in Table 4 .

Table 4. Sensitivity analysis on the knock-on effect of the fund gap (unit: trillion yuan) ${ }^{1}$.

\begin{tabular}{cccccccc}
\hline Sensitive Factor & $\begin{array}{c}\text { Reference } \\
\text { Value }\end{array}$ & $\begin{array}{c}\text { High-Speed } \\
\text { Value }\end{array}$ & $\begin{array}{c}\text { High Rate } \\
\text { of Change }\end{array}$ & Elasticity & $\begin{array}{c}\text { Low-Speed } \\
\text { Value }\end{array}$ & $\begin{array}{c}\text { Low Rate of } \\
\text { Change }\end{array}$ & $\begin{array}{c}\text { Elasticity } \\
\text { Enterprise contribution rate }\end{array}$ \\
116.730 & 111.554 & -0.044 & -0.709 & 120.081 & 0.029 & -0.459 \\
Wage growth rate & 116.730 & 104.758 & -0.103 & -0.599 & 148.919 & 0.276 & -1.611 \\
Urbanization rate & 116.730 & 116.325 & -0.003 & -0.237 & 117.225 & 0.004 & -0.289 \\
Pension growth rate & 116.730 & 143.236 & 0.227 & 1.135 & 99.059 & -0.151 & 0.757 \\
Age of receiving pension & 106.884 & 95.485 & -0.107 & -2.091 & 152.683 & 0.428 & -3.539 \\
\hline
\end{tabular}

${ }^{1}$ Rate of change $=($ variable value - reference value $) /$ reference value.

The results of the sensitivity analysis in Table 4 show that the fiscal risk of CEBPS under longevity risk is inversely related to the enterprise contribution rate, wage growth rate, urbanization rate, and age of receiving pension, and is positively related to the pension growth rate. Compared with the benchmark case, the elasticity of the wage growth rate is -0.599 under the high-speed scheme and -1.611 under the low-speed scheme, and the reduction of wage growth rate has a more significant impact on financial risk. The elasticity of the basic pension growth rate is 1.135 under the high-speed scheme and 0.757 under the low-speed scheme, and an increase in pension growth rate significantly increases fiscal risk. The elasticity of the age of receiving pension is -2.091 under the high-speed scheme and -3.539 under the low-speed scheme. Thus, the age of receiving pension has the most significant impact on fiscal risk. Therefore, the age growth rate, basic pension 
growth rate, and age of receiving pension have significant impacts on fiscal risk, whereas the urbanization rate has a relatively limited effect. Increasing the wage growth rate, reducing the basic pension growth rate, and delaying retirement could reduce the fiscal risk of CEBPS.

\section{Conclusions}

Considering the mortality data of all age groups in China from 1994 to 2017 as historical data and taking into account the lack of static mortality, we used the Lee-Carter model to predict dynamic mortality of all age groups in China from 2018 to 2067 under longevity risk. We then established an income and expenditure prediction model of CEBPS in combination with the actual payment and distribution methods in China. Using relevant actual data of China, we predicted the fund income and expenditure of CEBPS and the confidence interval of the fund balance in the next 50 years, and analyzed the impact of longevity risk on the income and expenditure of the fund and the fund gap. At the same time, we used a more general risk measurement method to analyze the fiscal risk of CEBPS under longevity risk and to analyze the knock-on effect of fiscal risk.

Our results lead to the following conclusions. (1) The dependency ratio of the elderly in China is increasing year by year, the remaining life of retirees is increasing, and some employees are retiring. Women's desire for childbirth is low in China. In this background, fund income and expenditure increase exponentially, the rate of increase of fund expenditure is much greater than that of fund income, the fund gap continues to exist and expand rapidly, the fund gap in later stages is tens or hundreds of times that of the current fund gap, and the sustainability of the pension insurance fund is low under existing policies. (2) Under longevity risk, the income and expenditure gap of CEBPS fluctuates greatly, which is likely to cause fiscal risk. The $2.5 \%$ and $97.5 \%$ quantiles of fund balance in 2067 are 1.52 and 0.44 times the expected value. The knock-on effect of fiscal risk measured by VaR is 1.15 times GDP and 4.75 times the state fiscal expenditure in 2020. (3) Under longevity risk, the fiscal risk of CEBPS is inversely related to the enterprise contribution rate, wage growth rate, urbanization rate, and age of receiving pension, and is positively related to the pension growth rate. (4) According to the above conclusions, the Chinese government should pay attention to the fiscal risk caused by longevity risk and consider not only the expected value but also the volatility of the CEBPS fund gap. The government can try to take the following three measures to reduce the fiscal risk of CEBPS: increasing the wage growth rate, decreasing the basic pension growth rate, and delaying retirement.

With population ageing becoming a world-wide trend, the fiscal risk of the basic pension insurance system under longevity risk has occurred or is about to occur in most countries. In this article, we attempted to measure the fiscal risk caused by longevity risk and provide policy basis for the government. We took a person as the basic unit for more accurate calculations in the income and expenditure model and introduced more general risk measurement methods into the research, which was important to put forward more precise and targeted measures to prevent fiscal risk in the pension insurance system. Our research has a strong reference significance for researchers facing the same problem. Because this article makes some assumptions about the parameters and does not consider policy changes, subsequent studies can attempt to change some parameter settings or consider policy changes to enrich the research on the fiscal risk of the basic pension insurance system under longevity risk.

Author Contributions: Conceptualization, M.L. and D.P.; resources and writing-original draft preparation, M.L. and X.X.; investigation and data curation, Q.L.; writing-review and editing, M.L. and D.P. All authors have read and agreed to the published version of the manuscript.

Funding: This research was funded by the China National Social Science Fund, grant number 17CSH018, Fundamental Research Funds for the Central Universities in UIBE, grant number 19YB14, and the Program for Innovation Research in Central University of Finance and Economics.

Institutional Review Board Statement: Not applicable. 
Informed Consent Statement: Not applicable.

Data Availability Statement: Not applicable.

Conflicts of Interest: The authors declare no conflict of interest.

Appendix A. Estimated Values of Parameters $\alpha_{x}$ and $\beta_{x}$ of Male and Female

\begin{tabular}{|c|c|c|c|c|}
\hline \multirow{2}{*}{$\begin{array}{c}\text { Gender } \\
\text { Age } \backslash \text { Parameters }\end{array}$} & \multicolumn{2}{|c|}{ Male } & \multicolumn{2}{|c|}{ Female } \\
\hline & $\alpha_{x}$ & $\beta_{x}$ & $\alpha_{x}$ & $\beta_{x}$ \\
\hline 0 & -4.62156 & 0.03271 & -4.38418 & 0.02688 \\
\hline 1 & -6.57001 & 0.02045 & -6.69297 & 0.02041 \\
\hline 2 & -7.00203 & 0.02498 & -7.01375 & 0.02014 \\
\hline 3 & -7.20135 & 0.02155 & -7.30388 & 0.01379 \\
\hline 4 & -7.36729 & 0.02054 & -7.68324 & 0.01845 \\
\hline 5 & -7.52433 & 0.02074 & -7.95896 & 0.02046 \\
\hline 6 & -7.72190 & 0.01231 & -8.12368 & 0.01075 \\
\hline 7 & -7.62413 & 0.01199 & -8.18860 & 0.01375 \\
\hline 8 & -7.65736 & 0.01433 & -8.17953 & 0.01186 \\
\hline 9 & -7.76815 & 0.00256 & -8.23297 & 0.00833 \\
\hline 10 & -7.81154 & 0.01327 & -8.05884 & 0.00919 \\
\hline 11 & -8.09005 & 0.01938 & -7.96781 & 0.00664 \\
\hline 12 & -8.03120 & 0.00917 & -8.19955 & 0.01490 \\
\hline 13 & -7.76556 & 0.00978 & -8.22248 & 0.02053 \\
\hline 14 & -7.72090 & 0.01125 & -8.16831 & 0.01040 \\
\hline 15 & -7.64872 & 0.01023 & -7.99545 & 0.01770 \\
\hline 16 & -7.55858 & 0.01105 & -8.05549 & 0.00548 \\
\hline 17 & -7.43028 & 0.02019 & -7.99888 & 0.01434 \\
\hline 18 & -7.27804 & 0.01939 & -7.67284 & 0.01495 \\
\hline 19 & -7.12622 & 0.01435 & -7.61026 & 0.01545 \\
\hline 20 & -7.09375 & 0.01772 & -7.84089 & 0.01710 \\
\hline 21 & -6.85488 & 0.01066 & -7.84289 & 0.01658 \\
\hline 22 & -6.95970 & 0.01249 & -7.70703 & 0.02261 \\
\hline 23 & -7.04901 & 0.01194 & -7.48115 & 0.02173 \\
\hline 24 & -6.99608 & 0.01458 & -7.69706 & 0.02197 \\
\hline 25 & -7.00353 & 0.01483 & -7.57436 & 0.02047 \\
\hline 26 & -6.93059 & 0.01595 & -7.52795 & 0.01453 \\
\hline 27 & -6.94696 & 0.01032 & -7.63655 & 0.02301 \\
\hline 28 & -6.85357 & 0.01518 & -7.50668 & 0.01774 \\
\hline 29 & -6.78187 & 0.01044 & -7.50092 & 0.02005 \\
\hline 30 & -6.69146 & 0.01362 & -7.31876 & 0.01801 \\
\hline 31 & -6.60542 & 0.01285 & -7.47704 & 0.01452 \\
\hline 32 & -6.60853 & 0.00635 & -7.36607 & 0.01439 \\
\hline 33 & -6.60972 & 0.01400 & -7.19650 & 0.01105 \\
\hline 34 & -6.46795 & 0.00980 & -7.24633 & 0.01135 \\
\hline 35 & -6.33917 & 0.00811 & -7.30183 & 0.01783 \\
\hline 36 & -6.42502 & 0.00989 & -7.23281 & 0.01244 \\
\hline 37 & -6.40468 & 0.00844 & -7.04852 & 0.00960 \\
\hline 38 & -6.22751 & 0.00639 & -7.02321 & 0.01133 \\
\hline 39 & -6.14788 & 0.00515 & -6.75124 & 0.01060 \\
\hline 40 & -6.04110 & 0.00769 & -6.80048 & 0.00792 \\
\hline 41 & -6.08234 & 0.00677 & -6.66756 & 0.01047 \\
\hline 42 & -5.96965 & 0.00471 & -6.63577 & 0.00521 \\
\hline 43 & -5.90425 & 0.00671 & -6.55378 & 0.00840 \\
\hline 44 & -5.89315 & 0.00712 & -6.49435 & 0.00855 \\
\hline 45 & -5.75320 & 0.00450 & -6.43030 & 0.00979 \\
\hline
\end{tabular}




\begin{tabular}{|c|c|c|c|c|}
\hline \multirow{2}{*}{$\begin{array}{c}\text { Gender } \\
\text { Age } \backslash \text { Parameters }\end{array}$} & \multicolumn{2}{|c|}{ Male } & \multicolumn{2}{|c|}{ Female } \\
\hline & $\alpha_{x}$ & $\beta_{x}$ & $\alpha_{x}$ & $\beta_{x}$ \\
\hline 46 & -5.64048 & 0.00633 & -6.28376 & 0.00640 \\
\hline 47 & -5.61615 & 0.00852 & -6.22656 & 0.00627 \\
\hline 48 & -5.45081 & 0.00626 & -6.17575 & 0.01115 \\
\hline 49 & -5.39686 & 0.00629 & -5.98499 & 0.00895 \\
\hline 50 & -5.31300 & 0.00450 & -5.94701 & 0.00760 \\
\hline 51 & -5.20185 & 0.00620 & -5.81607 & 0.00893 \\
\hline 52 & -5.18605 & 0.00417 & -5.74637 & 0.00870 \\
\hline 53 & -5.09421 & 0.00531 & -5.72730 & 0.01126 \\
\hline 54 & -5.00930 & 0.00517 & -5.56433 & 0.00628 \\
\hline 55 & -4.88421 & 0.00757 & -5.50715 & 0.00825 \\
\hline 56 & -4.79198 & 0.00561 & -5.41774 & 0.00657 \\
\hline 57 & -4.75442 & 0.00600 & -5.26577 & 0.00683 \\
\hline 58 & -4.59815 & 0.00754 & -5.13659 & 0.01009 \\
\hline 59 & -4.48090 & 0.00847 & -5.06904 & 0.00748 \\
\hline 60 & -4.37499 & 0.00657 & -4.93217 & 0.00864 \\
\hline 61 & -4.30909 & 0.00854 & -4.94986 & 0.00941 \\
\hline 62 & -4.15282 & 0.00951 & -4.72151 & 0.00921 \\
\hline 63 & -4.10731 & 0.00923 & -4.59292 & 0.00770 \\
\hline 64 & -4.02560 & 0.00934 & -4.55246 & 0.00917 \\
\hline 65 & -3.93652 & 0.00719 & -4.41630 & 0.00979 \\
\hline 66 & -3.79845 & 0.00881 & -4.31074 & 0.00807 \\
\hline 67 & -3.71748 & 0.00815 & -4.24819 & 0.00725 \\
\hline 68 & -3.62275 & 0.00895 & -4.06680 & 0.00784 \\
\hline 69 & -3.50980 & 0.00932 & -3.91371 & 0.00726 \\
\hline 70 & -3.37198 & 0.00975 & -3.83106 & 0.00877 \\
\hline 71 & -3.25782 & 0.00906 & -3.73532 & 0.00711 \\
\hline 72 & -3.18089 & 0.00824 & -3.60911 & 0.00818 \\
\hline 73 & -3.07531 & 0.00733 & -3.55004 & 0.00815 \\
\hline 74 & -3.03662 & 0.00715 & -3.44068 & 0.00845 \\
\hline 75 & -2.90625 & 0.00678 & -3.28499 & 0.00804 \\
\hline 76 & -2.79576 & 0.00780 & -3.23901 & 0.00723 \\
\hline 77 & -2.67531 & 0.00853 & -3.05641 & 0.00601 \\
\hline 78 & -2.61787 & 0.00868 & -2.97738 & 0.00606 \\
\hline 79 & -2.51028 & 0.00728 & -2.88624 & 0.00527 \\
\hline 80 & -2.42028 & 0.00726 & -2.71385 & 0.00549 \\
\hline 81 & -2.25320 & 0.00894 & -2.62181 & 0.00672 \\
\hline 82 & -2.22365 & 0.00676 & -2.55495 & 0.00591 \\
\hline 83 & -2.11842 & 0.00828 & -2.40772 & 0.00719 \\
\hline 84 & -2.03546 & 0.00918 & -2.35070 & 0.00550 \\
\hline 85 & -2.00357 & 0.00768 & -2.25595 & 0.00512 \\
\hline 86 & -1.88175 & 0.00552 & -2.16679 & 0.00494 \\
\hline 87 & -1.75388 & 0.00791 & -2.12763 & 0.00396 \\
\hline 88 & -1.69046 & 0.00788 & -1.99767 & 0.00314 \\
\hline 89 & -1.58424 & 0.00835 & -1.86394 & 0.00400 \\
\hline 90 & -1.53899 & 0.00797 & -1.81861 & 0.00483 \\
\hline 91 & -1.49201 & 0.00656 & -1.73445 & 0.00494 \\
\hline 92 & -1.39869 & 0.00752 & -1.64709 & 0.00482 \\
\hline 93 & -1.33766 & 0.00773 & -1.55747 & 0.00417 \\
\hline 94 & -1.26771 & 0.00698 & -1.49454 & 0.00462 \\
\hline 95 & -1.20362 & 0.00788 & -1.42283 & 0.00418 \\
\hline 96 & -1.13022 & 0.00670 & -1.34921 & 0.00406 \\
\hline 97 & -1.06942 & 0.00684 & -1.29018 & 0.00369 \\
\hline 98 & -0.99529 & 0.00915 & -1.19799 & 0.00382 \\
\hline 99 & -0.93120 & 0.00941 & -1.17475 & 0.00095 \\
\hline
\end{tabular}


Appendix B. Estimated Values of Parameter $k_{t}$ of Male and Female

\begin{tabular}{ccc}
\hline Time $\backslash$ Gender & Male & Female \\
\hline 1994 & 33.2084 & 51.3184 \\
1995 & 39.4429 & 49.1193 \\
1996 & 33.5458 & 40.9681 \\
1997 & 31.7851 & 38.0873 \\
1998 & 32.5188 & 32.8505 \\
1999 & 19.4786 & 34.7427 \\
2000 & 21.4609 & 32.5212 \\
2001 & 21.6200 & 18.2203 \\
2002 & 13.7045 & 18.4637 \\
2003 & 10.2823 & 21.4180 \\
2004 & 10.0631 & 12.6208 \\
2005 & 10.3486 & 4.6885 \\
2006 & -10.6914 & -9.2847 \\
2007 & -11.5040 & -10.1855 \\
2008 & -0.5283 & -12.6329 \\
2009 & -27.0173 & -20.4423 \\
2010 & -16.1270 & -19.2904 \\
2011 & -18.8028 & -23.2862 \\
2012 & -16.2574 & -24.9482 \\
2013 & -20.6983 & -30.0364 \\
2014 & -21.4034 & -38.9570 \\
2015 & -46.0050 & -58.1271 \\
2016 & -45.7643 & -51.0063 \\
2017 & -47.0511 & -56.8212 \\
\hline
\end{tabular}

Appendix C. Stationary Processing, ARMA Model Selection, Parameter Estimation, and Model Applicability Test of the ARIMA (p, d, q) Model

Table A1. ADF test of male $k_{t}$.

\begin{tabular}{cccc}
\hline Original Hypothesis & \multicolumn{2}{c}{ There Is a Unit Root in K1 Sequence } \\
\hline $\begin{array}{c}\text { Model Form } \\
\text { Lag Order }\end{array}$ & Intercept Term 2 (Based on SiC Test, the Maximum Lag Order Is 5) \\
& & $\boldsymbol{t}$ Value & $\boldsymbol{p}$ Value \\
\hline ADF test statistics & & 0.6178 & 0.9867 \\
& $1 \%$ & -3.7880 & \\
Significance level & $5 \%$ & -3.0124 & \\
& $10 \%$ & -2.6461 & \\
\hline
\end{tabular}

Table A2. ADF test of female $k_{t}$.

\begin{tabular}{|c|c|c|c|}
\hline Original Hypothesis & \multicolumn{3}{|c|}{ There Is a Unit Root in K2 Sequence } \\
\hline \multirow{2}{*}{$\begin{array}{l}\text { Model Form } \\
\text { Lag Order }\end{array}$} & \multicolumn{3}{|c|}{ Intercept Term 0 (Based on $\mathrm{SiC}$ Test, the Maximum Lag Order Is 5) } \\
\hline & & $t$ Value & $p$ Value \\
\hline \multirow[t]{2}{*}{ ADF test statistics } & & -0.0954 & 0.9389 \\
\hline & $1 \%$ & -3.7529 & \\
\hline \multirow[t]{2}{*}{ Significance level } & $5 \%$ & -2.9981 & \\
\hline & $10 \%$ & -2.6388 & \\
\hline
\end{tabular}


Table A3. Unit root test of first order difference of male $k_{t}$.

\begin{tabular}{cccc}
\hline Original Hypothesis & \multicolumn{2}{c}{ The First Order Difference Sequence of K1 has a Unit Root } \\
\hline $\begin{array}{c}\text { Model Form } \\
\text { Lag Order }\end{array}$ & \multicolumn{2}{c}{ Intercept Term 1 (Based on SiC Test, the Maximum Lag Order Is 5) } \\
\hline & & $\boldsymbol{t}$ Value & $\boldsymbol{p}$ Value \\
\hline ADF test statistics & $1 \%$ & -5.5445 & 0.0002 \\
Significance level & $5 \%$ & -3.7880 & \\
& $10 \%$ & -3.0124 & \\
\hline
\end{tabular}

Table A4. Unit root test of first order difference of female $k_{t}$.

\begin{tabular}{cccc}
\hline Original Hypothesis & \multicolumn{2}{c}{ The First Order Difference Sequence of K2 has a Unit Root } \\
\hline $\begin{array}{c}\text { Model Form } \\
\text { Lag Order }\end{array}$ & \multicolumn{2}{c}{ Intercept Term 0 (Based on SiC Test, the Maximum Lag Order Is 5) } \\
\hline & & $T$ Value & $\boldsymbol{p}$ Value \\
\hline ADF test statistics & $1 \%$ & -5.7388 & 0.0001 \\
Significance level & $5 \%$ & -3.7696 & \\
& $10 \%$ & -3.0049 & \\
\hline
\end{tabular}

Table A5. Autocorrelation and partial correlation of first order difference of male $k_{t}$.

\begin{tabular}{|c|c|c|c|c|c|c|c|c|}
\hline \multicolumn{2}{|c|}{$\begin{array}{l}\text { Sample Years } \\
\text { Sample Size }\end{array}$} & \multicolumn{6}{|c|}{$\begin{array}{c}1994-2017 \\
23\end{array}$} & \multirow[b]{2}{*}{$p$ Value } \\
\hline \multicolumn{2}{|c|}{$\begin{array}{c}\text { Autocorrelation } \\
\text { Graph }\end{array}$} & \multicolumn{2}{|c|}{$\begin{array}{c}\text { Partial } \\
\text { Autocorrelation } \\
\text { Graph }\end{array}$} & \multirow{2}{*}{$\begin{array}{c}\text { Lag Phase } \\
1\end{array}$} & \multirow{2}{*}{$\begin{array}{c}\begin{array}{c}\text { Autocorrelation } \\
\text { Value }\end{array} \\
-0.462\end{array}$} & \multirow{2}{*}{$\begin{array}{c}\text { Partial } \\
\begin{array}{c}\text { Autocorrelation } \\
\text { Value }\end{array} \\
-0.462\end{array}$} & \multirow{2}{*}{$\begin{array}{c}\text { Q Statistic } \\
5.5693\end{array}$} & \\
\hline & & 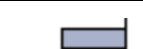 & 1 & & & & & 0.018 \\
\hline 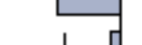 & 1 & 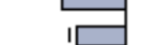 & 1 & 2 & -0.071 & -0.361 & 5.7063 & 0.058 \\
\hline 1 & 1 & 1 & I & 3 & 0.178 & -0.049 & 6.6137 & 0.085 \\
\hline 1 & । & 1 & I & 4 & -0.071 & -0.009 & 6.7658 & 0.149 \\
\hline 1 & 1 & $1 \square$ & I & 5 & -0.209 & -0.282 & 8.1599 & 0.148 \\
\hline 1 & 1 & 1 든 & I & 6 & 0.191 & -0.14 & 9.3913 & 0.153 \\
\hline 1 & । & 1 & 1 & 7 & 0.003 & -0.028 & 9.3916 & 0.226 \\
\hline 든 & 1 & d & I & 8 & -0.123 & -0.082 & 9.9715 & 0.267 \\
\hline b & 1 & I & I & 9 & 0.101 & -0.056 & 10.389 & 0.320 \\
\hline । 口 & 1 & 1 & 1 & 10 & 0.14 & 0.153 & 11.251 & 0.338 \\
\hline $1 \square$ & । & 1 & I & 11 & -0.217 & 0.015 & 13.507 & 0.261 \\
\hline 17 & 1 & प & 1 & 12 & 0.02 & -0.095 & 13.527 & 0.332 \\
\hline
\end{tabular}

Table A6. Autocorrelation and partial correlation of first order difference of female $k_{t}$.

\begin{tabular}{|c|c|c|c|c|c|c|c|c|}
\hline \multicolumn{2}{|c|}{$\begin{array}{l}\text { Sample Years } \\
\text { Sample Size }\end{array}$} & \multicolumn{6}{|c|}{$\begin{array}{c}1994-2017 \\
23\end{array}$} & \multirow[b]{2}{*}{$p$ Value } \\
\hline \multicolumn{2}{|c|}{$\begin{array}{l}\text { Autocorrelation } \\
\text { Graph }\end{array}$} & \multicolumn{2}{|c|}{$\begin{array}{c}\text { Partial } \\
\text { Autocorrelation } \\
\text { Graph }\end{array}$} & \multirow{2}{*}{$\begin{array}{c}\text { Lag Phase } \\
1\end{array}$} & \multirow{2}{*}{$\begin{array}{c}\begin{array}{c}\text { Autocorrelation } \\
\text { Value }\end{array} \\
-0.241\end{array}$} & \multirow{2}{*}{$\begin{array}{c}\text { Partial } \\
\begin{array}{c}\text { Autocorrelation } \\
\text { Value }\end{array} \\
-0.241\end{array}$} & \multirow{2}{*}{$\begin{array}{c}\text { Q Statistic } \\
1.5158\end{array}$} & \\
\hline 마 & I & $1 \square$ & 1 & & & & & 0.218 \\
\hline $1 \square$ & 1 & $1 \square$ & I & 2 & -0.215 & -0.289 & 2.7764 & 0.250 \\
\hline 1 & 1 & 1 & । & 3 & -0.049 & -0.215 & 2.8453 & 0.416 \\
\hline 1 & I & 1 口 & । & 4 & 0.001 & -0.176 & 2.8453 & 0.584 \\
\hline 1 & 1 & 1 & । & 5 & 0.082 & -0.051 & 3.0594 & 0.691 \\
\hline 1 & I & 1 & । & 6 & -0.088 & -0.153 & 3.3206 & 0.768 \\
\hline $1 \square$ & 1 & 1 & I & 7 & -0.206 & -0.359 & 4.839 & 0.680 \\
\hline 1 & 1 & $1 \square$ & I & 8 & 0.163 & -0.163 & 5.8517 & 0.664 \\
\hline 1 & 1 & 17 & 1 & 9 & 0.189 & 0.008 & 7.3199 & 0.604 \\
\hline 1 & 1 & 1 & 1 & 10 & -0.026 & 0.003 & 7.3499 & 0.692 \\
\hline 1 & 1 & 10 & । & 11 & -0.028 & 0.069 & 7.3867 & 0.767 \\
\hline $1 \square$ & 1 & $1 \square$ & 1 & 12 & -0.209 & -0.181 & 9.6739 & 0.645 \\
\hline
\end{tabular}


Table A7. Regression results of male ARIMA model.

\begin{tabular}{ccccc}
\hline Model & AIC & AC & Log Maximum Likelihood Estimation & Are the Parameters Significant? \\
\hline ARIMA $(0,1,0)$ & 6.580521 & 6.7297 & -66.09547 & No \\
ARIMA $(0,1,1)$ & 6.21557 & 6.3143 & -69.479 & Yes \\
ARIMA $(0,1,2)$ & 6.198652 & 6.34676 & -68.28449 & No \\
ARIMA $(1,1,0)$ & 6.546365 & 6.64555 & -70.01001 & No \\
ARIMA $(1,1,1)$ & 5.58491 & 5.73368 & -58.43401 & No \\
ARIMA $(1,1,2)$ & 5.53601 & 5.73439 & -56.89617 & No \\
ARIMA $(2,1,0)$ & 6.58021 & 6.72934 & -66.09547 & No \\
ARIMA $(2,1,1)$ & 6.35593 & 6.55489 & -62.73731 & No \\
ARIMA $(2,1,2)$ & 6.435176 & 6.683872 & & \\
\hline
\end{tabular}

Table A8. Regression results of female ARIMA model.

\begin{tabular}{ccccc}
\hline Model & AIC & AC & Log Maximum Likelihood Estimation & Are the Parameters Significant? \\
\hline ARIMA $(0,1,0)$ & 7.4249 & 7.4743 & -83.3867 & No \\
ARIMA $(0,1,1)$ & 6.8043 & 6.9030 & -72.2491 & Yes \\
ARIMA $(0,1,2)$ & 6.8909 & 7.0390 & -76.2458 & No \\
ARIMA $(1,1,0)$ & 7.2607 & 7.3599 & -77.8679 & Nes \\
ARIMA $(1,1,1)$ & 6.1173 & 6.2660 & -72.2808 & No \\
ARIMA $(1,1,2)$ & 6.9346 & 7.1330 & -72.9941 & No \\
ARIMA $(2,1,0)$ & 7.2375 & 7.38670 & -60.5841 & No \\
ARIMA $(2,1,1)$ & 6.1509 & 6.3498 & -68.8342 & No \\
ARIMA $(2,1,2)$ & 7.0318 & 7.2805 & & \\
\hline
\end{tabular}

Table A9. White noise test of male residual sequence.

\begin{tabular}{|c|c|c|c|c|c|c|c|c|}
\hline \multicolumn{2}{|c|}{$\begin{array}{l}\text { Sample Years } \\
\text { Sample Size }\end{array}$} & \multicolumn{6}{|c|}{ 1994-2017 } & \multirow[b]{2}{*}{$p$ Value } \\
\hline \multicolumn{2}{|c|}{$\begin{array}{l}\text { Autocorrelation } \\
\text { Graph }\end{array}$} & \multicolumn{2}{|c|}{$\begin{array}{c}\text { Partial Autocorrelation } \\
\text { Graph }\end{array}$} & Lag Phase & $\begin{array}{c}\text { Autocorrelation } \\
\text { Value }\end{array}$ & $\begin{array}{c}\text { Partial Autocorrelation } \\
\text { Value }\end{array}$ & $\begin{array}{c}\mathrm{Q} \\
\text { Statistic }\end{array}$ & \\
\hline & 1 & 1 & h 1 & 1 & -0.055 & -0.055 & 0.0799 & \\
\hline 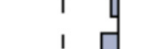 & 1 & 1 & 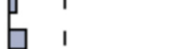 & 2 & -0.125 & -0.128 & 0.5058 & 0.477 \\
\hline 14 & 1 & I & 1 & 3 & -0.025 & -0.041 & 0.5241 & 0.769 \\
\hline 1 & I & I & $\sqsupseteq$ । & 4 & -0.197 & -0.222 & 1.6967 & 0.638 \\
\hline (4 & I & 1 & ए & 5 & -0.335 & -0.401 & 5.2864 & 0.259 \\
\hline 1 & 1 & 1 & 曰 & 6 & 0.052 & -0.123 & 5.3787 & 0.371 \\
\hline j & 1 & 1 & 巨 1 & 7 & 0.044 & -0.142 & 5.4470 & 0.488 \\
\hline 1 & 1 & 1 & $\sqsupseteq$ ○ & 8 & -0.024 & -0.205 & 5.4693 & 0.603 \\
\hline b & 1 & 1 & D 1 & 9 & 0.138 & -0.133 & 6.2533 & 0.619 \\
\hline E & 1 & 1 & 1 & 10 & 0.195 & -0.013 & 7.9296 & 0.541 \\
\hline 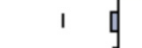 & 1 & 1 & p 1 & 11 & -0.055 & -0.094 & 8.0753 & 0.621 \\
\hline I & 1 & 1 & 5 & 12 & -0.038 & -0.103 & 8.1495 & 0.700 \\
\hline
\end{tabular}

Table A10. White noise test of female residual sequence.

\begin{tabular}{|c|c|c|c|c|c|c|}
\hline \multirow{2}{*}{$\begin{array}{c}\text { Sample Years } \\
\text { Sample Size } \\
\begin{array}{c}\text { Autocorrelation } \\
\text { Graph }\end{array}\end{array}$} & \multicolumn{5}{|c|}{$\begin{array}{c}1994-2017 \\
23\end{array}$} & \multirow[b]{2}{*}{$p$ Value } \\
\hline & $\begin{array}{c}\text { Partial Autocorrelation } \\
\text { Graph }\end{array}$ & Lag Phase & $\begin{array}{c}\text { Autocorrelation } \\
\text { Value }\end{array}$ & $\begin{array}{c}\text { Partial Autocorrelation } \\
\text { Value }\end{array}$ & $\underset{\text { Statistic }}{\mathbf{Q}}$ & \\
\hline $1 \quad \longmapsto 1$ & & 1 & 0.284 & 0.284 & 2.1038 & \\
\hline$1 \longdiv { 1 }$ & ו & 2 & -0.12 & -0.218 & 2.4987 & 0.114 \\
\hline $10 \quad 1$ & । & 3 & -0.206 & -0.117 & 3.7214 & 0.156 \\
\hline $1 \square \quad$ & 14 & 4 & -0.215 & -0.159 & 5.123 & 0.163 \\
\hline 14 & 1 & 5 & -0.161 & -0.12 & 5.9498 & 0.203 \\
\hline 14 & $1 \square$ & 6 & -0.199 & -0.24 & 7.2929 & 0.200 \\
\hline 1 무 & $1 \square$ & 7 & -0.206 & -0.247 & 8.8191 & 0.184 \\
\hline 1马 1 & 1 & 8 & 0.127 & 0.1 & 9.4399 & 0.223 \\
\hline$\square$ & $p$ & 9 & 0.3 & 0.072 & 13.142 & 0.107 \\
\hline 曰 & 1 & 10 & 0.171 & -0.046 & 14.429 & 0.108 \\
\hline $1 \quad 1$ & 1 & 11 & 0.049 & 0 & 14.544 & 0.150 \\
\hline 1 다 1 & 1 디 & 12 & -0.122 & -0.126 & 15.325 & 0.168 \\
\hline
\end{tabular}


Appendix D. Predicted Values of Parameter $k_{t}$

\begin{tabular}{|c|c|c|}
\hline Time & Predicted Values of Male & Predicted Values of Female \\
\hline 2018 & -50.2707 & -61.7373 \\
\hline 2019 & -54.1598 & -66.6538 \\
\hline 2020 & -58.0489 & -71.5704 \\
\hline 2021 & -61.9380 & -76.4869 \\
\hline 2022 & -65.8271 & -81.4035 \\
\hline 2023 & -69.7162 & -86.3201 \\
\hline 2024 & -73.6053 & -91.2366 \\
\hline 2025 & -77.4944 & -96.1532 \\
\hline 2026 & -81.3835 & -101.0697 \\
\hline 2027 & -85.2726 & -105.9863 \\
\hline 2028 & -89.1618 & -110.9029 \\
\hline 2029 & -93.0509 & -115.8194 \\
\hline 2030 & -96.9400 & -120.7360 \\
\hline 2031 & -100.8291 & -125.6525 \\
\hline 2032 & -104.7182 & -130.5691 \\
\hline 2033 & -108.6073 & -135.4857 \\
\hline 2034 & -112.4964 & -140.4022 \\
\hline 2035 & -116.3855 & -145.3188 \\
\hline 2036 & -120.2746 & -150.2353 \\
\hline 2037 & -124.1637 & -155.1519 \\
\hline 2038 & -128.0528 & -160.0685 \\
\hline 2039 & -131.9419 & -164.9850 \\
\hline 2040 & -135.8310 & -169.9016 \\
\hline 2041 & -139.7201 & -174.8181 \\
\hline 2042 & -143.6092 & -179.7347 \\
\hline 2043 & -147.4984 & -184.6513 \\
\hline 2044 & -151.3875 & -189.5678 \\
\hline 2045 & -155.2766 & -194.4844 \\
\hline 2046 & -159.1657 & -199.4009 \\
\hline 2047 & -163.0548 & -204.3175 \\
\hline 2048 & -166.9439 & -209.2341 \\
\hline 2049 & -170.8330 & -214.1506 \\
\hline 2050 & -174.7221 & -219.0672 \\
\hline 2051 & -178.6112 & -223.9837 \\
\hline 2052 & -182.5003 & -228.9003 \\
\hline 2053 & -186.3894 & -233.8169 \\
\hline 2054 & -190.2785 & -238.7334 \\
\hline 2055 & -194.1676 & -243.6500 \\
\hline 2056 & -198.0567 & -248.5665 \\
\hline 2057 & -201.9459 & -253.4831 \\
\hline 2058 & -205.8350 & -258.3997 \\
\hline 2059 & -209.7241 & -263.3162 \\
\hline 2060 & -213.6132 & -268.2328 \\
\hline 2061 & -217.5023 & -273.1493 \\
\hline 2062 & -221.3914 & -278.0659 \\
\hline 2063 & -225.2805 & -282.9825 \\
\hline 2064 & -229.1696 & -287.8990 \\
\hline 2065 & -233.0587 & -292.8156 \\
\hline 2066 & -236.9478 & -297.7321 \\
\hline 2067 & -240.8369 & -302.6487 \\
\hline
\end{tabular}

\section{References}

1. Blake, D.; Mayhew, L. On the sustainability of the UK state pension system in the light of population ageing and declining fertility. Econ. J. 2006, 116, F286-F305. [CrossRef]

2. Jimeno, J.F.; Rojas, J.A.; Puente, S. Modelling the impact of aging on social security expenditures. Econ. Model. 2008, 25, 201-224. [CrossRef] 
3. Sonsbeek, J. Micro simulations on the effects of ageing-related policy measures: The social affairs department of the Netherlands ageing and pensions model. Econ. Model. 2010, 27, 968-979. [CrossRef]

4. Chomik, R.; Piggott, J. Pensions, ageing and retirement in Australia: Long term projections and policies. Aust. Econ. Rev. 2012, 45, 350-361. [CrossRef]

5. Bonenkamp, J.; Meijdam, L.; Ponds, E.; Westerhout, E. Ageing-driven pension reforms. J. Popul. Econ. 2017, 30, 953-976. [CrossRef]

6. Barr, N. Economics of the Welfare State, 4th ed.; Oxford University Press: New York, NY, USA, 2004; p. 204.

7. Zaidi, A. Population aging and financial and social sustainability challenges of pension systems in Europe: A cross-national perspective. In The Future of Multi-Pillar Pensions; Bovenberg, L., Ewijk, C.V., Westerhout, E., Eds.; Cambridge University Press: Cambridge, UK, 2012; pp. 17-45.

8. Liu, B.; Yang, Z. Population aging shock and fiscal sustainability in china: Mechanism analysis and effect simulation. Singap. Econ. Rev. 2018. [CrossRef]

9. Brixi, H.P.; Schick, A. Government at Risk: Contingent Liabilities and Fiscal Risk; Oxford University Press: New York, NY, USA, 2002; pp. 2-3.

10. Zhao, Q.; Mi, H. Evaluation on the sustainability of urban public pension system in China. Sustainability 2019, 11, 1418. [CrossRef]

11. U.S. Congressional Budget Office. Quantifying Uncertainty in the Analysis of Long-term Social Security Projections; U.S. Congressional Budget Office: Washington, DC, USA, 2005.

12. Metzger, C. An actuarial balance sheet of the Swiss old-age pension scheme. Int. Soc. Secur. Rev. 2018, 71, 25-49. [CrossRef]

13. Belolipetskii, A.A.; Lepskaya, M.A. A Mathematical Model of Pension Fund Operation and Methods of Fund Stability Analysis. Comput. Math. Model. 2018, 29, 233-243. [CrossRef]

14. Lee, D.R.; Carter, R.L. Modeling and forecasting US mortality. J. Inst. Actuar. 1860, 13, 325-358.

15. Girosi, F.; Kin, G. Understanding the Lee-Carter Mortality Forecasting Method. 2007. Available online: http://gking.harvard. edu/files/abs/lc-abs.shtml (accessed on 20 November 2020).

16. Chernyavskiy, P.; Little, M.P.; Rosenberg, P.S. A unified approach for assessing heterogeneity in age-period-cohort model parameters using random effects. Stat. Methods Med Res. 2019, 28, 20-34. [CrossRef]

17. Cairns, A.J.G.; Blake, D.P.; Dowd, K. A two-factor model for stochastic mortality with parameter uncertainty: Theory and calibration. J. Risk Insur. 2006, 73, 687-718. [CrossRef]

18. Carfora, M.F.; Cutillo, L.; Orlando, A. A quantitative comparison of stochastic mortality models on Italian population data. Comput. Stat. Data Anal. 2017, 112, 198-214. [CrossRef]

19. Jing, P.; Chang, C.; Zhu, H.; Hu, Q. Financial imbalance risk and its control strategy of China's pension insurance contribution rate reduction. Math. Probl. Eng. 2021, 12. [CrossRef]

20. Zhao, Y.; Bai, M.; Liu, Y.; Hao, J. Quantitative analyses of transition pension liabilities and solvency sustainability in China. Sustainability 2017, 9, 2252. [CrossRef]

21. Wang, H.; Huang, J.; Yang, Q. Assessing the financial sustainability of the pension plan in china: The role of fertility policy adjustment and retirement delay. Sustainability 2019, 11, 883. [CrossRef]

22. Sun, L.; Su, C.; Xian, X. Assessing the sustainability of china's basic pension funding for urban and rural residents. Sustainability 2020, 12, 2833. [CrossRef]

23. Tian, Y.; Zhao, X. Stochastic forecast of the financial sustainability of basic pension in China. Sustainability 2016, 8, 46. [CrossRef]

24. Chen, X.; Yang, Z. Stochastically assessing the financial sustainability of individual accounts in the urban enterprise employees' pension plan in china. Sustainability 2019, 11, 3568. [CrossRef]

25. Xie, Y.; Zhang, X.; Lv, H.; Guo, X. The new fertility policy and the actuarial balance of china urban employee basic endowment insurance fund based on stochastic mortality model. Math. Probl. Eng. 2020, 3, 1-12.

26. Zhao, Y.; Bai, M.; Peng, F.; Zhu, M. Stochastic assessments of urban employees' pension plan of china. Sustainability 2018, 10, 1028. [CrossRef]

27. Koissi, M.C.; Shapiro, A.F.; Hognas, G. Evaluating and extending the Lee-carter mortality forecasting:Bootstrap confidence interval. Insur. Math. Econ. 2006, 38, 1-20. [CrossRef]

28. Wilmoth, J.R. Mortality projections for Japan: A comparison of four methods. In Health and Mortality among Elderly Population; Oxford University Press: New York, NY, USA, 1996.

29. Liao, P.; Su, H.; Pamučar, D. Will Ending the One-Child Policy and Raising the Retirement Age Enhance the Sustainability of China's Basic Pension System? Sustainability 2020, 12, 8172. [CrossRef] 